\title{
The HIV-1 viral synapse signals human foreskin keratinocytes to secrete thymic stromal lymphopoietin facilitating HIV-1 foreskin entry
}

\author{
Z Zhou ${ }^{1,2,3}$, L Xu ${ }^{1,2,3}$, A Sennepin ${ }^{1,2,3}$, C Federici ${ }^{2,3}$, Y Ganor ${ }^{1,2,3}$, D Tudor ${ }^{1,2,3}$, \\ D Damotte ${ }^{4}$, N Barry Delongchamps ${ }^{5}, \mathrm{M}_{Z^{2}}$ Zerbib $^{5}$ and $\mathrm{M} \mathrm{Bomsel}^{1,2,3}$
}

The complexity of signal transduction resulting from the contact of human immunodeficiency virus type 1 (HIV-1)infected cells and mucosal cells has hampered our comprehension of HIV-1 mucosal entry. Such process is driven efficiently only by viral synapse contacts, whereas cell-free HIV-1 remains poorly infectious. Using CD4 ${ }^{+}$T-cells expressing only HIV-1 envelope inoculated on human adult foreskin tissues, we designed methodologies to identify the signals transduced in foreskin keratinocytes following HIV-1-envelope-dependent viral synapse formation. We find that the viral synapse activates the MyD88-independent TLR-4-nuclear factor (NfkB) signaling pathway in keratinocytes and the subsequent secretion of cytokines including thymic stromal lymphopoietin (TSLP), a cytokine linking innate and T-helper type 2-adaptive immune responses. Moreover, the viral synapse upregulates the non-coding microRNA miR-375, known to control TSLP, and transfection of keratinocytes with anti-miR-375 blocks significantly TSLP secretion. Thus, the secretion of TSLP by keratinocytes is induced by the viral synapse in a miR-375 controlled manner. At the tissue level, these signals translate into the epidermal redistribution of Langerhans cells and formation of conjugates with T-cells, recapitulating the initial events observed in human foreskin infection by HIV-1. These results open new possibilities for designing strategies to block mucosal HIV-1 transmission, the major pathway by which HIV-1 spreads worldwide.

\section{INTRODUCTION}

The human immunodeficiency virus type 1 (HIV-1), such as enveloped viruses from various families, can disseminate both by fluid-phase diffusion of cell-free viral particles and by cellto-cell transfer of viruses formed extemporaneously at the cellcell contacts. Although infection of T-cells by cell-free HIV-1 is the best-studied mechanism of HIV-1 infection, cell-to-cell transfer of HIV-1 following viral synapse formation between HIV-1-infected cells, such as CD4 ${ }^{+}$T-cells, macrophages, or dendritic cells (DCs), and adjacent T-cells has proven to be more efficient. ${ }^{1-3}$ The molecular mechanisms controlling viral synapse-induced HIV-1 transfer have mainly been described for cells expressing the HIV-1 receptor CD4 and co-receptors CCR5 or CXCR $4 .{ }^{4-6}$ However, we have previously shown that the formation of viral synapses with mucosal CD4-negative epithelial cells also presides to HIV-1 penetration via transcytosis across the cervical/intestinal barrier ${ }^{7,8}$ and human urethral tissues ex vivo, ${ }^{9}$ with a 100 -fold higher efficiency than cell-free viruses. ${ }^{10,11}$ HIV-1 cell-to-cell transfer also resists blockade by various types of anti-viral agents such as antiretroviral molecules or in some cases, neutralizing antibodies, emphasizing the efficiency of cell-to-cell-dependent spread of HIV-1, as compared to cell-free viral particles. ${ }^{12,13}$

Viral synapses also constitute the chief mechanism for HIV-1 infection of adult human foreskin mucosa, one major site of HIV-1 mucosal entry during sexual intercourse. ${ }^{14}$ Hence, male circumcision reduces by $>60 \%$ the rate of sexual HIV-1 acquisition in men. In this regard, we recently demonstrated that HIV-1-infected cell-dependent viral synapses are rapidly formed with the inner foreskin mucosa. ${ }^{15,16}$ There, HIV-1 virions produced in the synaptic cleft, but not cell-free HIV-1, are rapidly captured by Langerhans cell (LC) and transferred to $\mathrm{CD} 4{ }^{+} \mathrm{T}$-cells across conjugates formed between these two cell types. However in this process, the role of epithelial cells,

${ }^{1}$ Mucosal Entry of HIV-1 and Mucosal Immunity, Infection, Immunity and Inflammation Department, Cochin Institute, Université Paris Descartes, Paris, France. ${ }^{2}$ INSERM, U1016, Paris, France. ${ }^{3}$ CNRS, UMR 8104, Paris, France. ${ }^{4}$ Anatomy and Pathological Cytology Service, GH Cochin-St Vincent de Paul, Paris, France and ${ }^{5}$ Urology Service, GH Cochin-St Vincent de Paul, Paris, France. Correspondence: M Bomsel (morgane.bomsel@inserm.fr) 
forming an obstacle between HIV-1-infected cells and LCs, has not been defined.

Although epithelial cells such as keratinocytes have been considered for many years only as physical and non-selective barriers, recent studies have identified keratinocytes as immune sentinels able to sense pathogens using Toll-like receptors (TLRs) and then to mediate immune responses. ${ }^{17}$ Epidermal keratinocytes express various TLRs, including the intracellular TLR-3 and surface express TLR- $4,{ }^{18}$ capable of sensing pathogenassociated molecular patterns such as polyinosine-polycytidylic acid (poly I:C) or lipopolysaccharide (LPS), respectively. This in turn allows for the secretion of various chemokines and cytokines by the keratinocytes. Thus, keratinocytes appear to be key factors in epidermal innate immunity.

One of the cytokines expressed by keratinocytes is thymic stromal lymphopoietin (TSLP), an interleukin (IL)-7-like molecule initially identified as a B-cell growth factor. ${ }^{19}$ TSLP is produced by keratinocytes via NfkB-dependent pathway, ${ }^{20,21}$ and its level is increased at sites of inflammation. TSLP acts mainly as a cytokine with pro-inflammatory properties by activating DCs, and initiating a CD4 ${ }^{+}$T-helper type 2 cell response, or in contrast, promoting a non-inflammatory and tolerogenic environment. In addition, TSLP chemoattracts immune cells such as DCs. ${ }^{22}$ Cells respond to TSLP via a heterodimeric receptor consisting of a TSLP-specific binding chain, the TSLP receptor (TSLP-R), and the IL-7 receptor- $\alpha$ chain. This heterodimer are primarily expressed on DCs, activated T-lymphocytes, and mast cells. ${ }^{19}$ Hence, TLSP appears as one of the actors mediating the keratinocyteimmune crosstalk at the mucosal level.

One member of the evolutionarily conserved, small, non-coding microRNAs ( $\mathrm{miR}$ ) that regulate gene expression has been shown to regulate TSLP. Hence, in epithelial cells, miR-375 stimulates TSLP expression, thereby regulating the epithelium-immunologic crosstalk in the gut ${ }^{23}$ or in the airway bronchial epithelium. ${ }^{24}$

In this study, we used human primary foreskin keratinocytes and foreskin tissues ex vivo, two complementary cellular tissue models, to study the molecular mechanisms and signaling driven by the formation of the HIV-1-envelope-dependent viral synapse with human foreskin. We demonstrate that the HIV-1 envelope spike in the context of the viral synapse is sufficient to activate the secretion of TSLP by keratinocytes in a miR-375 controlled manner. In turn, TSLP attracts LCs-the initial targets of HIV-1 in the foreskin tissue-to the mucosal surface, thereby recapitulating the first phase of events in human foreskin infection by HIV-1.

\section{RESULTS}

Establishment of HIV-1-envelope-mediated viral synapses with human foreskin keratinocytes depends on gp120, LFA-1, and ICAM-1/3

We first established a three-dimensional polarized foreskin mucosal model using human foreskin keratinocytes purified from healthy adult donors based on our previous studies. ${ }^{15,16}$ After $72 \mathrm{~h}$ of culture on a basement membrane mimic, as described in the Methods section, an epithelium of three to four layers of polarized keratinocytes developed (Supplementary Figure S1a online). We sought to restrict our study to the signaling induced solely by cell-cell contact occurring during viral synapse formation between HIV-1-infected cells and the epithelial cells. Importantly, we wanted to circumvent signals induced later on by the budding of viral particles and viral endocytosis into, or fusion with the epithelium. We therefore used the human lymphoblastic T-cell line CEM expressing a functional HIV-1 envelope made of trimeric spikes of the gp41 and gp120 subunits (HIV-Env) ${ }^{25}$ mimicking the viral component of the viral synapse. HIV-Env were routinely labeled at $>90 \%$ efficiency by the gp120-specific $2 \mathrm{G} 12$ monoclonal antibody $(\mathrm{mAb})$ and the gp41-specific $98.6 \mathrm{mAb}$ using flow cytometry (Supplementary Figure S1b online). Furthermore, comparative evaluation of HIV-1 envelope expression using the broadly neutralizing antigp41 mAbs 4E10 and 10E8 indicates that HIV-1 envelope was not overexpressed on HIV-Env as compared to HIV-1 NDK-infected cells (Supplementary Figure S1d online).

To quantify the viral synapse events, HIV-Env and the parental cell line CEM, both fluorescently loaded with cell tracker, were inoculated at the mucosal surface of the reconstructed epithelium and observed dynamically for up to $1 \mathrm{~h}$ by live microscopy in a $37^{\circ} \mathrm{C}$ environment (Figure 1a). HIV-Env adhered specifically to the epithelial surface as compared to CEM in a time-dependent manner, reaching a maximum after $60 \mathrm{~min}$ of contact ( $490 \pm 36$ vs. $160 \pm 32$ cells per $\mathrm{mm}^{2}, P<0.005$; Figure 1b), suggesting that the present model accurately reconstitutes the formation of HIV-envelopemediated viral synapses within $1 \mathrm{~h}$ between HIV-infected cells and the foreskin surface, as we had observed previously. ${ }^{15}$

Viral synapse establishment and signaling have been reported to depend on adhesion molecules as well as on the interaction of the viral envelope glycoproteins with their target cell receptors. ${ }^{5,10}$ Similarly to parental CEM, upon evaluation by flow cytometry (Supplementary Figure S1c online), HIV-Env cell surface expressed integrins CD11 $\alpha$ and CD18 (LFA- $1 \alpha$ and $\beta$ ), CD54 (ICAM-1), and CD50 (ICAM-3). To evaluate the involvement of adhesion molecules in our viral synapse model, HIV-Env were preincubated with blocking $\mathrm{mAbs}$ to specific adhesion molecules prior to incubation with the reconstructed epithelium. MAbs to integrins LFA- $1 \alpha$ or $\beta$ and corresponding disintegrins, ICAM- $1 / 3$, significantly inhibited the formation of viral synapses (inhibition means \pm s.d.: $34 \pm 4 \%, P<0.005 ; 60 \pm 3 \%, P<0.005$; and $45 \pm 2 \%$, $P<0.005$, respectively; Figure 1c), as reported for other types of viral synapses. ${ }^{26,27}$ Of note, the co-culture did not upregulate the adhesion molecules LFA- $1 \alpha$ and $\beta$ or ICAM- $1 / 3$ on HIV-Env (Figure S1 pannel c).

The involvement of HIV-1 envelope protein subunits was next evaluated, using $\mathrm{mAb}$ to gp41 and gp 120 . Only the gp 120 $2 \mathrm{G} 12 \mathrm{mAb}$ blocked the viral synapse formation $(52 \pm 2 \%$, $P<0.05$ ), whereas interfering with gp41 using the 2F5 (Figure 1c) or the $98.6 \mathrm{mAbs}$ (not shown) had no blocking effect. Similarly, isotype antibodies, used as negative controls, did not interfere with the formation of viral synapse (Figure 1c).

To evaluate a potential synergy between cell adhesion molecules and the viral glycoprotein gp120 in synapse formation, 
a

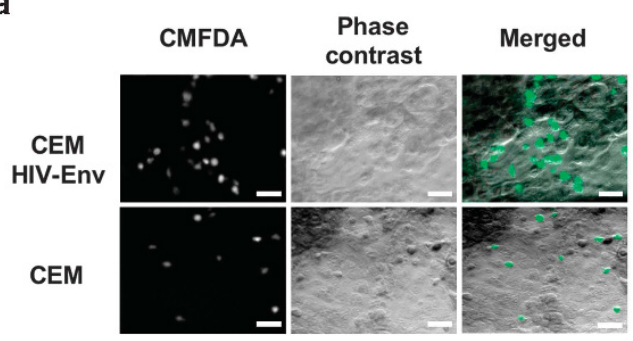

C
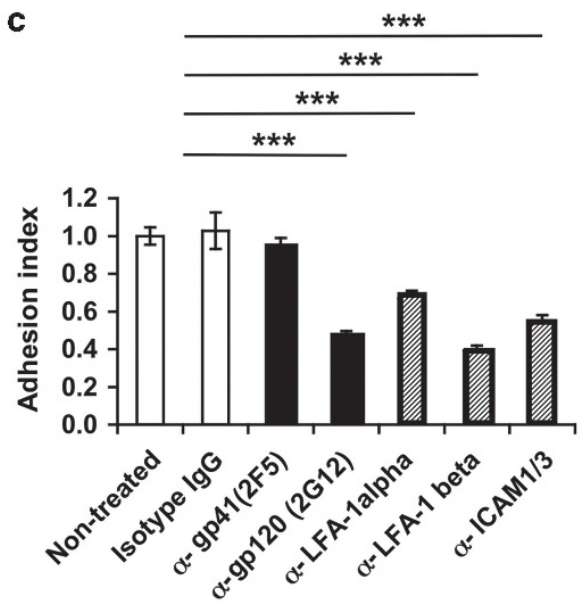

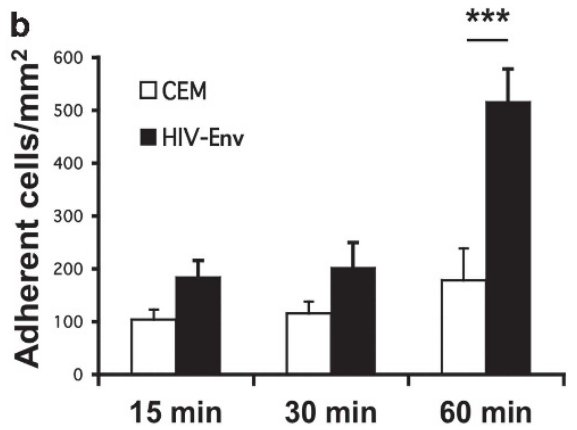

d

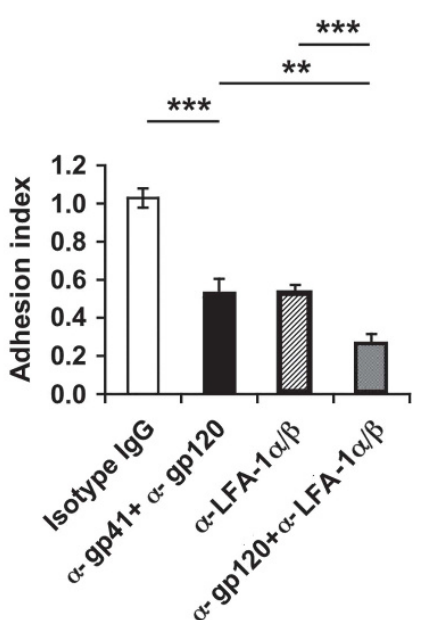

Figure 1 HIV-Env-mediated viral synapse formation depends on gp120 and LFA-1/ICAM-1/3. (a) HIV-Env, a CD4 ${ }^{+}$T-cell line expressing HIV envelope spikes, or the parental cells CEM were vitally labeled with CMFDA, inoculated in a polarized manner on a reconstructed epithelium (T-cell:keratinocyte ratio, 1:1) and observed using fluorescence live microscopy $1 \mathrm{~h}$. Shown are representative images of the CMFDA fluorescence (green), phase contrast, and the merging of both. Bar: $10 \mu \mathrm{m}$. (b) Quantification of HIV-Env (black bars) and CEM (empty bars) adhesion to the epithelium surface at 15,30 , and $60 \mathrm{~min}$ of contact. Shown are means \pm s.d. of $n=3$ independent experiments using keratinocytes from different individuals. (c,d) Viral synapse formation was analyzed after preincubation of $\mathrm{CD} 4^{+} \mathrm{T}$-cells with various antibodies either alone (c) or in combination (d), as indicated and adhesion evaluated as in $\mathbf{b}$. Shown are means \pm s.d. fold adhesion index (adherent HIV-Env per $\left.\mathrm{mm}^{2}\right) /\left(\right.$ adherent CEM per $\mathrm{mm}^{2}$ ) normalized to that in the absence of monoclonal antibody. $n \geq 3$ independent experiments. ${ }^{\star} P<0.05 ;{ }^{* \star} P<0.01 ;{ }^{* * *} P<0.005$ two-tailed paired Student's $t$-test

a combination of specific mAbs was used. Blocking HIV-1 subunits simultaneously, LFA- $1 \alpha$ and $\beta$ subunits simultaneously (Figure 1d) or LFA- $1 \alpha / \beta$ and epithelial or lymphocyte ICAM-1/3 (not shown) had no additional effect as compared to a single $\mathrm{mAb}$-induced synapse blockade. However, interfering simultaneously with gp120 and LFA- $1 \alpha / \beta$ significantly increased synapse blockade as compared to blocking only gp120 (mean inhibition \pm s.d.: $52 \pm 4 \%$ vs. $74 \pm 8 \%, P<0.01)$ or LFA $-1 \alpha / \beta$ (mean inhibition \pm s.d.: $49 \pm 4 \%$ vs. $74 \pm 8 \%, \quad P<0.005$; Figure 1d) suggesting a synergy.

Taken together, these results show that the formation of the HIV-Env-1-envelope-dependent viral synapse is mediated by gp120 but not gp41, and stabilized by LFA-1 and its desintegrins ICAM-1 and ICAM-3. Hence, our cellular model is appropriate to study signals transduced within the epithelium during viral synapse formation.

\section{The HIV-envelope-dependent viral synapse activates the TLR-4-NfкB pathway}

TLRs are activated during immune synapse formation. ${ }^{28} \mathrm{We}$ therefore evaluated whether similar activation was induced by the HIV-envelope-dependent viral synapse. First, TLR expression and activation in keratinocytes were studied. TLR-3 and -4 were found to be expressed by the reconstructed epithelium and were activated by their respective bona fide ligands, namely, Poly (I:C) and LPS, as shown by the timedependent-induced degradation of $\mathrm{I} \kappa \mathrm{B} \alpha$ the $\mathrm{Nf} \kappa \mathrm{B}$ regulator (Supplementary Figure S2a-c online), in agreement with Kawai et al. $^{29}$ Next, we examined whether formation of the HIV-envelope-mediated viral synapse could similarly activate the NfкB pathway. The reconstructed epithelium was incubated from 1 to $24 \mathrm{~h}$ with HIV-Env or CEM as a negative control, and I $\mathrm{K} \mathrm{B} \alpha$ expression was quantified by western blot. HIV-Env induced the degradation of I $\mathrm{B} \alpha$ in a time-dependent manner, reaching a maximum after $4 \mathrm{~h}$ of contact, whereas no significant change in $\mathrm{I} \kappa \mathrm{B} \alpha$ was observed after contact with parental CEM lacking HIV-envelope expression (Figure 2a,b). Furthermore, pretreatment of HIV-Env with the anti-gp120 $2 \mathrm{G} 12 \mathrm{mAb}$ blocked I $\mathrm{B} \alpha$ degradation (Figure 2c). Viral synapse-activated I $\mathrm{I} \mathrm{B} \alpha$ degradation was specific as pretreatment of keratinocytes with 4-hydroxynonenal, a $\mathrm{Nf \kappa B}$ inhibitor that prevents $\mathrm{I} \kappa \mathrm{B} \alpha$ phosphorylation, impaired $\mathrm{I} \kappa \mathrm{B} \alpha$ degradation (Figure 2c,d). In contrast, blocking the $\mathrm{Nf \kappa B}$ signaling 
b

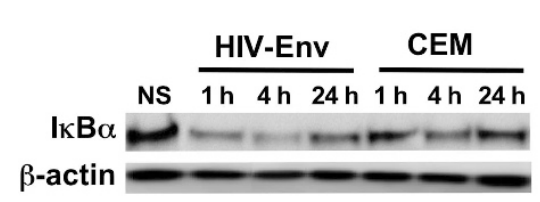

C

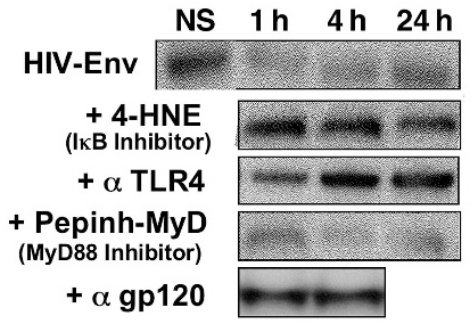

d
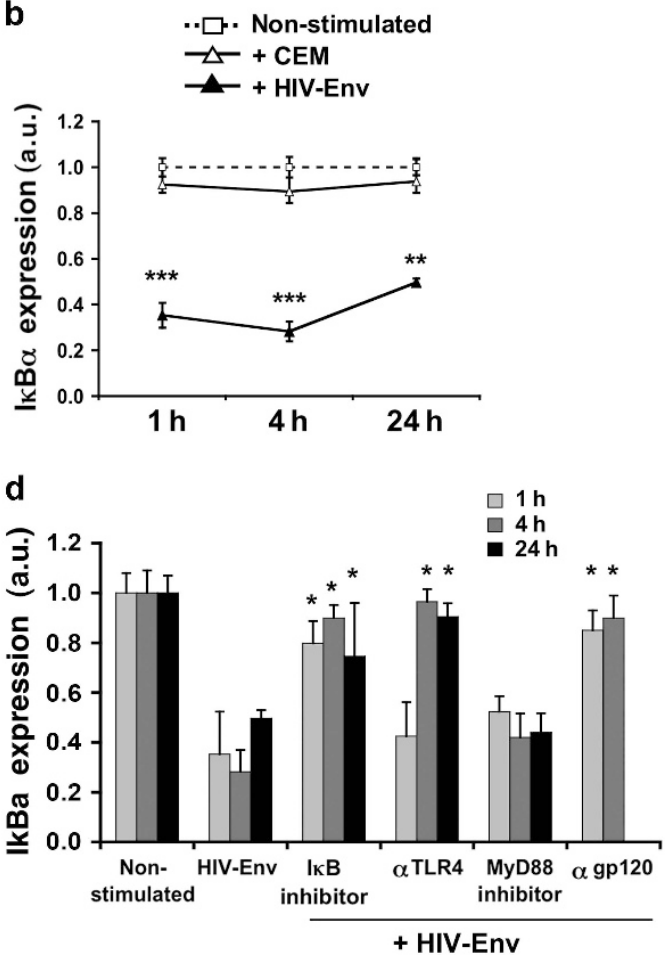

Figure 2 HIV-Env viral synapse formation induces TLR-4-dependent degradation of $I \kappa B \alpha$. (a) Epithelial I $\mathrm{k} \alpha$ degradation evaluated by western blot after contact of the keratinocyte epithelium with HIV-Env or parental CEM for 1, 4, and $24 \mathrm{~h}$ or left unstimulated (NS). I $\mathrm{kB} \alpha$ and $\beta$-actin immunoblots in (a) shown are representative of $n=5$ independent experiments using keratinocytes from different individuals. (b) Quantification of the IкB $\alpha$ immunoblot ( $n=5$ independent experiments using keratinocytes from different individuals) is shown as means \pm s.e.m. A two-tailed paired $t$-test was performed. (c) HIV-Env synapse-induced degradation of $I_{\kappa} B \alpha$ was assessed in the presence of 4-hydroxynonenal (4-HNE, I $\mathrm{kB} \alpha$ inhibitor), anti-TLR-4-neutralizing $\mathrm{mAb}(\alpha$-TLR-4), Pepinh-MyD (MyD88 inhibitor), or in the presence of $\alpha$-gp120 mAb. IкB $\alpha$ degradation was evaluated by immunoblotting as above. Immunoblots shown are representative of independent experiments using keratinocytes from $n=3$ different individuals. (d) Quantification of immunoblots in (c) ( $n=3$ independent experiments using keratinocytes from different individuals) is shown as means \pm s.e.m. ${ }^{\star} P<0.05 ;{ }^{\star *} P<0.01$; ${ }^{* \star *} P<0.005$ two-tailed paired $t$-test.

pathway using the MyD88 inhibitor Pepinh-MYD had no effect on $\mathrm{I} \kappa \mathrm{B} \alpha$ degradation. To define which particular TLR was the signal upstream to $\mathrm{I} \kappa \mathrm{B} \alpha$ degradation, the reconstructed epithelium was preincubated with TLR-3 or TLR-4-blocking mAbs. Preincubation with TLR-4-blocking mAb prevented $\mathrm{I} \kappa \mathrm{B} \alpha$ degradation induced by the HIV-Env-mediated viral synapse (Figure 2c,d), whereas TLR-3 mAb had no effect (not shown), pointing to a specific involvement of TLR-4 in this process.

Altogether, these results indicate that TLR-4 is activated by the HIV-Env-mediated viral synapse. In turn, TLR-4 activation turns on the $\mathrm{Nf \kappa B}$ signaling pathway dependent on $\mathrm{I} \kappa \mathrm{B} \alpha$ phosphorylation and subsequent degradation in a MyD88independent manner.

The classical TLR-4 pathway results in the activation of the I $\kappa$ B kinase (IKK), leading to phosphorylation of $I \kappa B \alpha$, which binds cytosolic NfкB p65 (RelA) subunit and prevents its nuclear translocation in resting cells. Following the proteasomal degradation of phosphorylated $\mathrm{I} \kappa \mathrm{B} \alpha, \mathrm{Nf} \kappa \mathrm{B}$ p 65 is released, activated, and translocates into the cell nucleus. Nuclear $\mathrm{Nf \kappa B}$ p65 binds to specific DNA fragments and initiates the translation and secretion of different cytokines and chemokines. ${ }^{29}$ We therefore tested whether the observed I $\mathrm{B} \alpha$ degradation induced by HIV-Env-mediated viral synapses similarly resulted in activation and nuclear translocation of NfкB p65. HIV-Env and parental CEM cells were allowed to form synapses with the reconstructed epithelium for 1 and $4 \mathrm{~h}$. LPS was used as a positive control for TLR- 4 activation. Cells were then fixed, nuclei labeled with 4,6-diamidino-2-phenylindole, NfผB p65 detected by immunofluorescence, and observed by confocal microscopy (Figure 3a). Contact with $\mathrm{HIV}$-Env induced a significant translocation of $\mathrm{Nf} \kappa \mathrm{B}$ p 65 from the cytoplasm into keratinocyte nuclei, identical to that observed after incubation with LPS. In contrast, in nonstimulated cells or in cells incubated with CEM lacking HIV envelope for up to $4 \mathrm{~h}, \mathrm{Nf \kappa B}$ p 65 remained located in the cytoplasm. Nf $\kappa \mathrm{B}$ p 65 translocation was further quantified using an algorithm computing the fluorescent intensity of $\mathrm{Nf \kappa B}$ p65 in each single nucleus as described in the Methods section. When compared with non-stimulated cells, NfкB p65 was significantly translocated in the nucleus within $1 \mathrm{~h}$ after formation of the HIV-Env-mediated synapses (non-stimulated $42.00 \pm 8.00$ vs. HIV-Env $79.05 \pm 26.96$ a.u., $P<0.05$ ), reaching the same level as LPS-induced translocation after $4 \mathrm{~h}$ (non-stimulated vs. HIV-Env: $128.39 \pm 34.69$ a.u., $P<0.01$, and vs. LPS: $120.87 \pm 26.00$ a.u., $P<0.01$ ), whereas $\mathrm{Nf \kappa B}$ p65 remained in the cytosol when CEM were inoculated onto the reconstructed epithelium (Figure $3 \mathbf{b}$ ). 
a

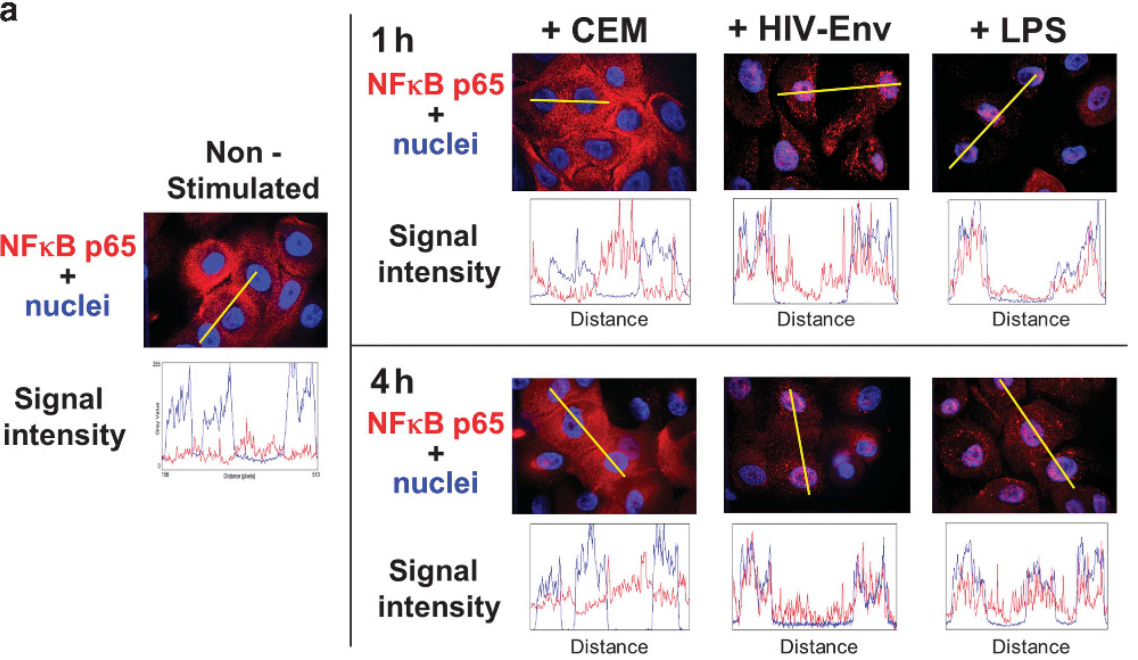

b

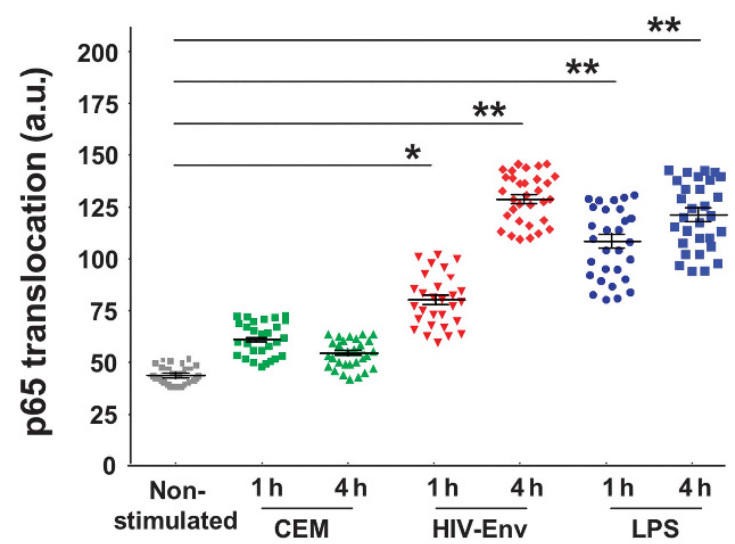

Figure 3 HIV-Env viral synapse formation induces NfкB p 65 nuclear translocation. (a) Reconstructed epithelia were inoculated with HIV-Env, CEM, or LPS for 1 and $4 \mathrm{~h}$, or were left non-stimulated. Epithelial localization of NfкB p65 was evaluated by immunofluorescence using anti-p65 monoclonal antibody and 4,6-diamidino-2-phenylindole (DAPI) to stain nuclei and observed by confocal microscopy. The intensity of the p65 signal along a line crossing nuclei (yellow lines) was evaluated using Image-J software. Shown are representative histograms indicating the distribution of $\mathrm{Nf} \kappa \mathrm{B}$ (red lines) in relation to the nucleus (blue lines) on single sections of $n=3$ independent experiments using keratinocytes from different individuals. Bar: $10 \mu \mathrm{m}$. (b) Images of each serial section (30 optical sections per region, $0.2 \mu \mathrm{m}$ apart, $n=3$ independent experiments using keratinocytes from different individuals) were further analyzed quantitatively using an Image-J-based stack intensity measurement program evaluating specifically the nuclear p65 signal through all the serial images. Signal intensities of $p 65$ over the entire stack were normalized and plotted. ${ }^{\star} P<0.05$; ${ }^{* * \star} P<0.005$, two-tailed paired Students' $t$-test. LPS, lipopolysaccharide; NfкB, nuclear factor $\kappa B$.

Taken together, these results indicate that the HIV-Env viral synapse activates the TLR-4-NfאB pathway.

TSLP, IL-6, IL-8, MMP-9, and MIG are secreted from the foreskin mucosa in response to the HIV-1-envelope-mediated viral synapse

Keratinocytes protect the mucosal surface against incoming pathogens by releasing innate immune factors, such as cytokines, chemokines, and defensins. This induction of innate immune factors is mainly controlled by TLR signaling. ${ }^{18}$ As we have shown above that the HIV-Env-mediated viral synapse induces the activation of TLR-4, most likely stimulated by gp120, we further investigated whether TLR-4-mediated Nf $\kappa B$ activation resulted in secretion of cytokines or chemokines. One of the cytokines induced in keratinocytes in a NfкBdependent manner is TSLP, ${ }^{19}$ whose messenger RNA was previously reported to be induced in non-polarized epithelial carcinoma-overexpressing p53 upon interaction with HIV-1 envelope gp $120 .^{30}$

We therefore determined whether the HIV-Env-mediated synapse induced the secretion of TSLP by keratinocytes. Incubation of the reconstructed epithelium with HIV-Env for 1 to $24 \mathrm{~h}$ induced a time-dependent secretion of TSLP, reaching $29.5 \pm 2.2 \mathrm{pg} \mathrm{ml}^{-1}$ after $24 \mathrm{~h}$, whereas no TSLP was secreted following incubation with CEM at any time point. LPS, used as a positive control, induced a robust TSLP secretion, although delayed as compared to HIV-Env stimulation (Figure 4a). Induction of TSLP secretion by the HIV-Env viral synapse occurred via a TLR-4/NfאB-dependent pathway, as a blocking TLR-4 mAb and the 4-hydroxynonenal I $\kappa \mathrm{B}$ inhibitor reduced TSLP secretion by $50 \%$ after $4 \mathrm{~h}$ and by $>60 \%$ after $24 \mathrm{~h}$, as compared to control $(P<0.005$, using keratinocytes from $n=3$ independent individuals; Figure $\mathbf{4 b}$ ). In contrast, the MyD88 inhibitor Perpin-MyD had no effect (not shown), confirming 
a
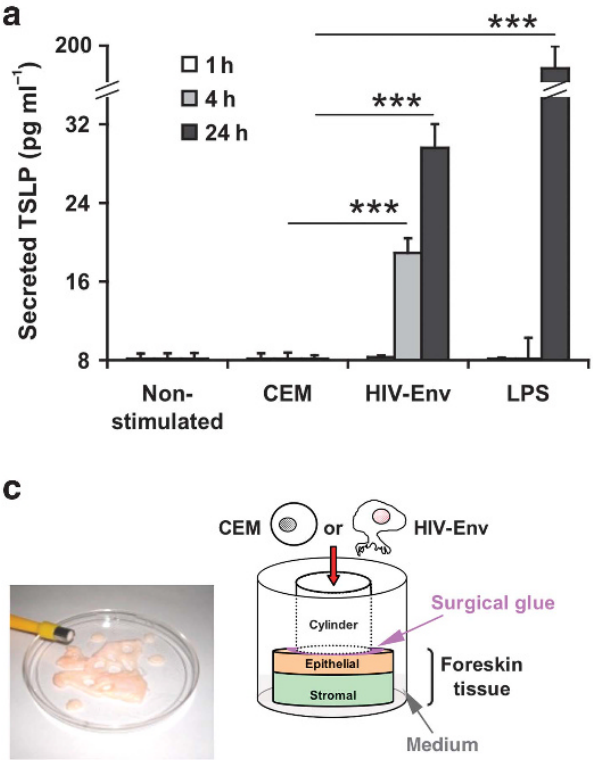

e

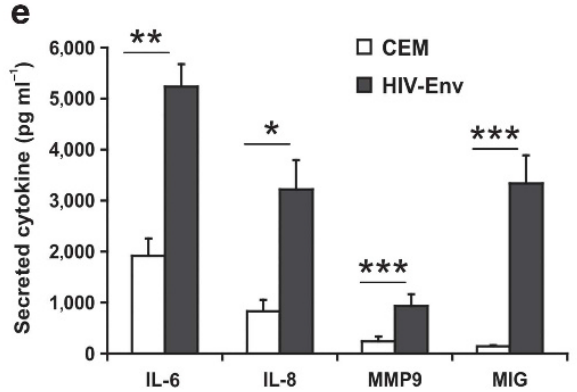

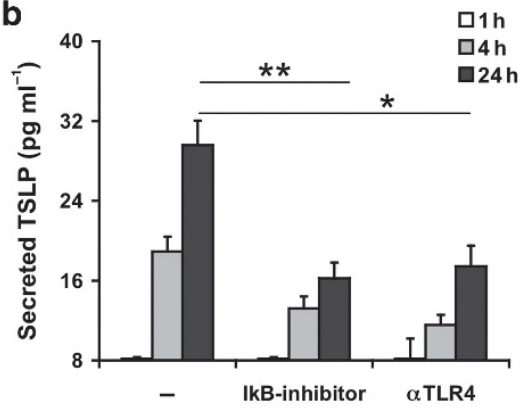

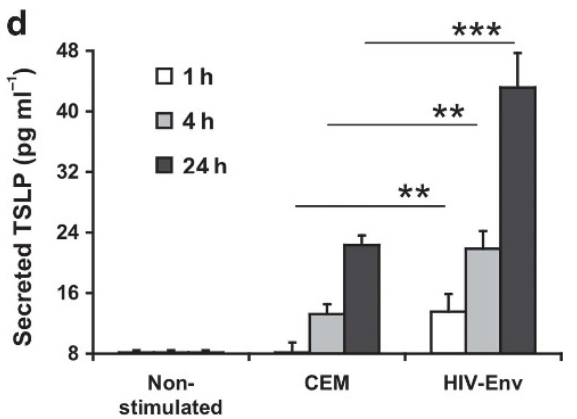

Figure 4 HIV-Env viral synapse formation induces TSLP secretion in vitro and ex vivo. (a) Reconstructed epithelia were inoculated with HIV-Env, parental CEM, or LPS as positive control or left unstimulated for 1, 4, and $24 \mathrm{~h}$. TSLP was measured by enzyme-linked immunosorbent assay (ELISA; sensitivity: $8 \mathrm{pg} \mathrm{ml}^{-1}$ ) in the cell culture medium. Shown are means \pm s.e.m. of $n=8$ independent experiments using keratinocytes from different individuals. (b) HIV-Env synapse assay was assessed in the presence of 4-hydroxynonenal (IKB inhibitor) or anti-TLR-4-neutralizing antibody ( $\alpha$-TLR-4) and TSLP evaluated as in a. Shown are means \pm s.e.m. of $n=6$ independent experiments using keratinocytes from different individuals. (c) A schematic representation of the experimental foreskin explant system. (d) Mean \pm s.e.m. of TSLP secretion after 1, 4 , and $24 \mathrm{~h}$ exposure of foreskin explants to HIV-Env or CEM, evaluated by ELISA. Results are derived from $n=4$ independent experiments using explants from different individuals.

(e) Mean \pm s.e.m. of IL-6, IL-8 (CXCL-8), MMP-9, and MIG (CXCL-9) secretion after $24 \mathrm{~h}$ exposure of foreskin explants to HIV-Env or CEM evaluated using a flowcytomix multiplex assay (sensitivity: IL-6: $1.2 \mathrm{pg} \mathrm{ml}^{-1}$, IL-8: $0.5 \mathrm{pg} \mathrm{ml}^{-1}$, MMP-9: $95 \mathrm{pg} \mathrm{ml}^{-1}$, and MIG: $0.95 \mathrm{pg} \mathrm{ml}{ }^{-1}$ ). Results are derived from $n=3$ independent experiments using explants from different individuals. ${ }^{*} P<0.05,{ }^{* *} P<0.01$, ${ }^{* * *} P<0.005$; unpaired Students' $t$-test. LPS, lipopolysaccharide; TSLP, thymic stromal lymphopoietin.

that TLR-4/NfאB-induced TSLP secretion occurred, but in a MyD88-independent manner. It probably differs from LPSdependent TSLP secretion that showed different kinetics of p65 translocation (Figure 3a) and TSLP secretion (Figure $\mathbf{4 b}$ ).

Similarly, when HIV-1 NDK chronically infected lymphocytes were incubated with the reconstructed epithelium for 8 and $20 \mathrm{~h}$, keratinocytes were induced to secrete TSLP in a timedependent manner, reaching $30.2 \pm 5.1$ and $46.5 \pm 5.1 \mathrm{pg} \mathrm{ml}^{-1}$ after 8 and $20 \mathrm{~h}$, respectively ( $n=3$ independent experiments with keratinocytes from different individuals).

We further confirmed these results using inner foreskin tissue explants incubated in a polarized manner with HIV-Env to allow for viral synapse formation (Figure 4c). HIV-Envmediated synapses stimulated TSLP secretion by inner foreskin explants in a time-dependent manner. TSLP was detectable by $1 \mathrm{~h}$ of contact, reaching $43.5 \pm 4.2 \mathrm{pg} \mathrm{ml}^{-1}$ after $24 \mathrm{~h}$ (Figure $4 \mathrm{~d}$ vs. control $P<0.005, n=3$ ), indicating that foreskin explants responded to HIV-Env even more efficiently than did the reconstructed epithelium in Figure 4a $(P<0.001$, using explants from $n=3$ independent individuals).

Next, secretion of other innate immune factors by inner foreskin explants upon viral HIV-envelope-mediated synapse formation was evaluated. The levels of 18 cytokines and chemokines were simultaneously measured in the culture medium after $24 \mathrm{~h}$ of synaptic contact, using a multiplex assay. Only IL-6, IL-8/CXCL-8, the matrix metalloproteinase (MMP)-9, and the monokine induced by gamma interferon (MIG/CXCL-9) were significantly secreted following incubation with HIV-Env-mediated synapses, as compared to foreskin explants incubated with CEM (Figure 4e). In contrast, neither CCL5 (RANTES) nor CCL20 (MIP-3 $\alpha$ ), which were secreted following incubation with HIV-1-infected cells, as we 


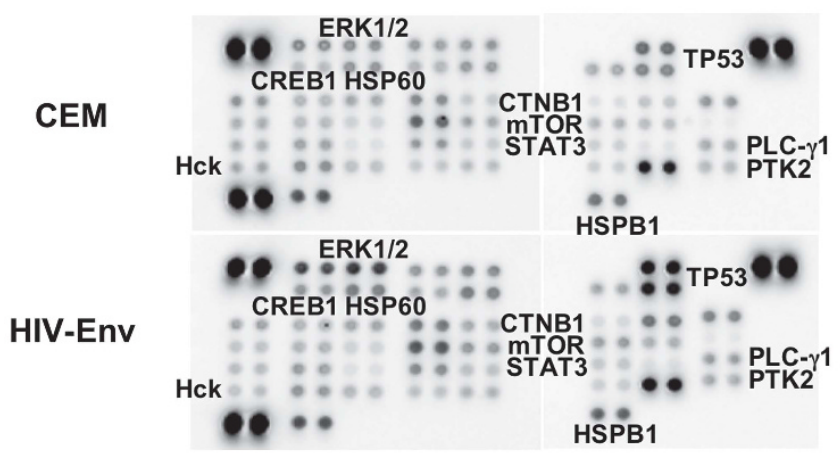

b

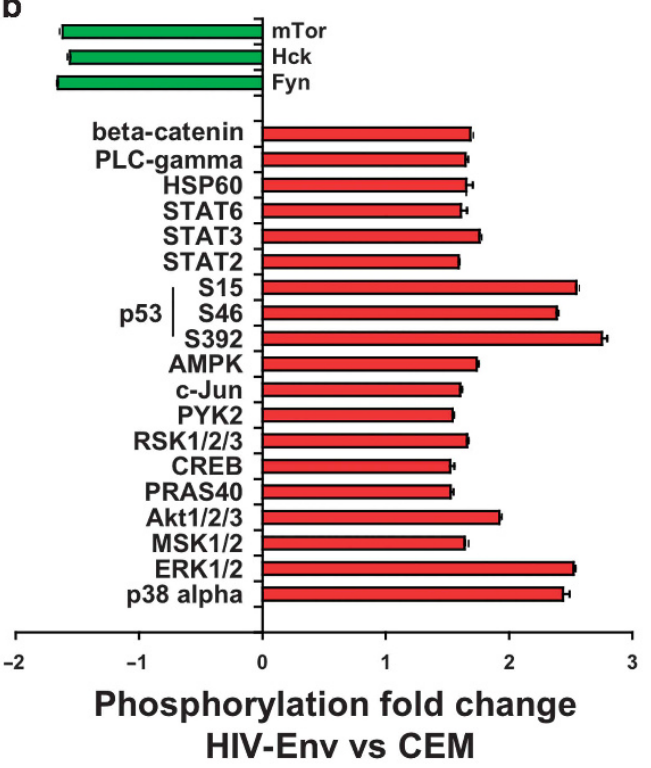

C

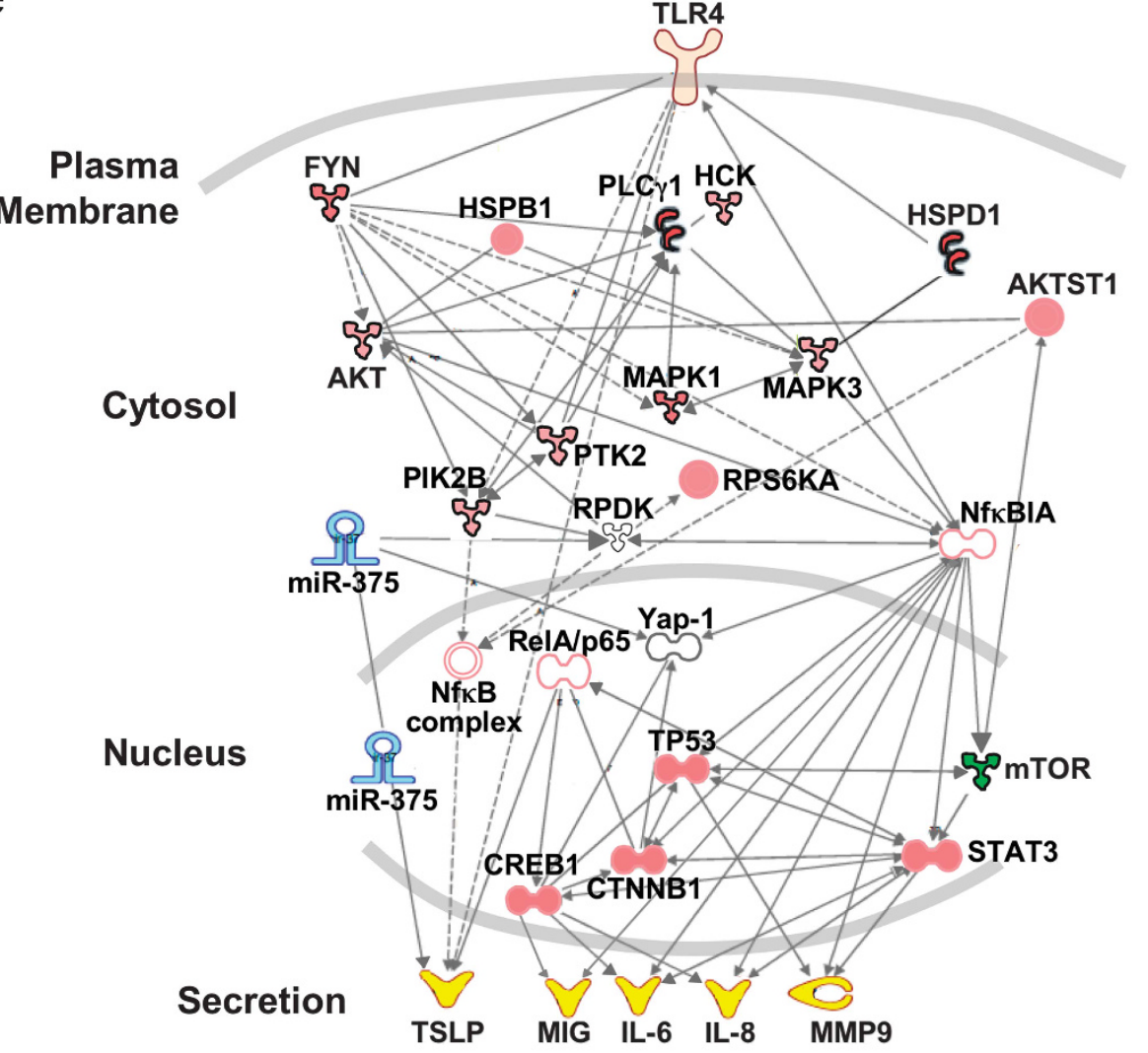

miRNA

Cytokines/Chemokines

\& Enzyme

(2) Complex

is Kinase

(C) Peptidase

Transcription regulator

() Receptor

Other

- Interaction

- - - Regulation

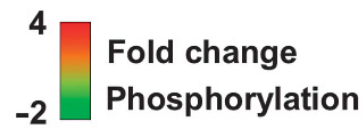

Figure 5 Phosphorylation and signal transduction induced by HIV-Env viral synapse establishment. (a) Phosphorylation of molecules in the TLR-4 signaling pathway examined by phosphoarray analysis of protein lysates ( $n=3$ independent individuals) prepared from reconstructed epithelia inoculated with HIV-Env or CEM for $4 \mathrm{~h}$. (b) Quantification based on pixel intensities of the phosphorylated targets. Graph represents phosphorylation fold changes following contact with HIV-Env vs. CEM. Cutoff is set at a fold change less than -1.5 or greater than 1.5. (c) Ingenuity Pathway Analysisgenerated network illustrating the signaling pathway generated specifically by the HIV-Env synapse in the reconstructed epithelium resulting in miR-375 expression and the secretion of TSLP and other innate factors. TSLP, thymic stromal lymphopoietin.

showed previously, ${ }^{15,16}$ nor G-CSF, IFN- $\gamma$, MIP- $1 \alpha$, MIP-1 $\beta$, MCP-1, nor TNF $\alpha$ were significantly secreted. In addition neither (not shown).
Therefore, HIV-envelope-mediated synapses are able to signal the secretion of specific innate immune factors including TSLP as well as IL-6, IL-8, MMP-9, and MIG that might act on 
a

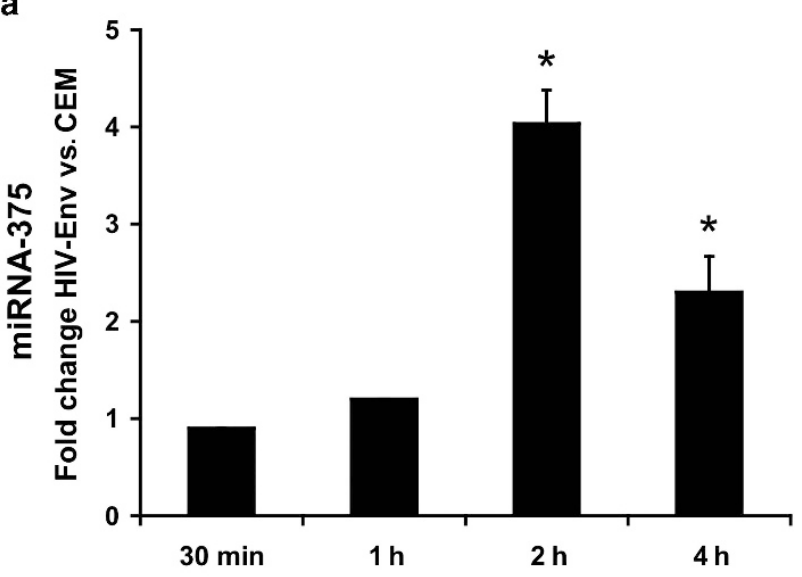

b

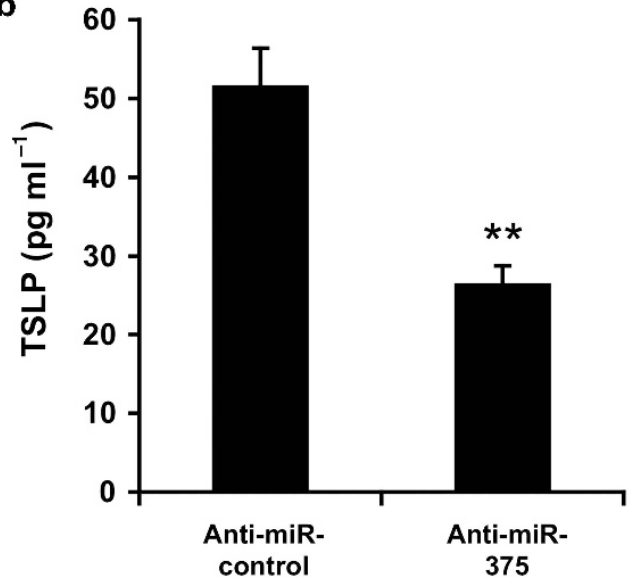

Figure 6 HIV-Env viral synapse formation induces expression of the microRNA miR-375 expression that regulates TSLP secretion. (a) Quantitative PCR analysis of the expression of miR-375 in the reconstructed epithelium exposed to HIV-Env for $30 \mathrm{~min}, 1,2$, and $4 \mathrm{~h}$ presented relative to the expression following exposure to CEM for the same time, respectively, set as 1 for non-stimulated epithelium. Shown are means \pm s.e.m. of $n=4$ independent experiments using keratinocytes from different individuals. ${ }^{*} P<0.02$; two-tailed Students' $t$-test as compared to non-stimulated. (b) Keratinocytes were transfected with miR-375 inhibitor (anti-miR-375) resulting in $53 \pm 3 \%$ inhibition of miR-375 or mock anti-miR (anti-miR control). Mean \pm s.e.m. of TSLP secretion by the resulting reconstructed epithelium after $24 \mathrm{~h}$ exposure to HIV-Env evaluated by enzyme-linked immunosorbent assay as in Figure 4. ${ }^{* \star} P<0.01$; unpaired Students' $t$-test; $n=3$ experiments. TSLP, thymic stromal lymphopoietin.

DCs and macrophages. It remains possible that the innate immune response induced by HIV-1-infected cell-mediated viral synapse would be wider than that the one mediated by HIV-Env we describe here.

The TLR-4-dependent secretion of TSLP by keratinocytes driven by the HIV-1-envelope-dependent viral synapse can be defined by phosphorylation arrays and pathway analysis

We next evaluated the steps in the TLR-4-/Nfik-dependent innate immune response pathway used by HIV-Env-dependent viral synapse for the secretion of TSLP and other innate immune factors. Reconstructed epithelia were incubated for $4 \mathrm{~h}$ with either HIV-Env or CEM; whole-cell lysates were obtained and proteins were examined by differential phosphoarray analysis (Figure 5a). The $4 \mathrm{~h}$ time point used was chosen as it appears optimal for the secretion of innate immune factors following viral synapse formation with foreskin explants (Figure 4, and our previous studies $\left.{ }^{15,16}\right)$. Differential quantification of the phosphoarray of 43 proteins (Figure $5 \mathbf{b}$ ) indicated that only three proteins, the Fyn and Hck kinases and mTor, showed reduced phosphorylation, whereas 16 other proteins showed increased phosphorylation, including mitogen-activated protein kinase p38 $\alpha$ and p53 at its three phosphorylation sites, as well as the extracellular signal-related kinase $1 / 2$.

On the basis of this protein phosphorylation pattern, pathway analysis using Pathway Studio and Ingenuity Pathway Analysis software showed that formation of the HIV-Env viral synapse induces an innate immune response dependent on TLR-4/I $\mathrm{B} \alpha / \mathrm{p} 65$ (Figure 5c). This pathway ultimately results in the secretion of TSLP, IL-6, IL-8/CXCL-8, MMP-9, and MIG/CXCL-9, in agreement with the experiments shown above (Figure 4). In addition, this pathway analysis suggested that induction of TSLP was regulated by the non-coding microRNA-375 (miR-375), as in other epithelia. ${ }^{23,24}$

The HIV-Env-dependent viral synapse induces miR-375 expression in reconstructed epithelium that controls TSLP secretion

To validate the pathway analysis regarding the activation of miR-375 by HIV-Env-dependent viral synapse, we incubated the reconstructed epithelium for $30 \mathrm{~min}$ to $4 \mathrm{~h}$ with either HIVEnv or CEM. Whole-cell extracts were obtained and miR-375 expression was evaluated by quantitative PCR (Figure 6a). MiR-375 expression increased significantly in a time-dependent manner to a maximum of $4.02 \pm 0.34$-fold at $2 \mathrm{~h}(P<0.001$ as compared to non-stimulated, using keratinocytes from $n=3$ independent individuals) after stimulation by HIV-Env as compared to CEM and then decreased to $2.30 \pm 0.37$ fold at $4 \mathrm{~h}(P<0.05$ as compared to $4 \mathrm{~h}$ or to non-stimulated, $n=3)$.

To determine whether miR-375 was necessary for upregulation of TSLP secretion by keratinocyte mediated by HIV-Env, we transfected primary keratinocyte with a miRNA-375 inhibitor (anti-miR-375) or with a mock inhibitor (anti-miR control) as control. Transfection resulted in a reduction of miR-375 by $53 \%$, \pm 3 in anti-miR-375, as compared to anti-miR control transfected cells, as expected from Bleck et al. ${ }^{24}$ Transfected cells were then stimulated with HIV-Env. After $24 \mathrm{~h}$ of contact, anti-miR-375 treatment reduced by $51.3 \pm 4.7 \% \quad(P<0.01$ comparing anti-miR-375 and anti-miR control treatment, $n=3$ ) the secretion of TSLP by keratinocytes, as compared to anti-miR control treatment (Figure 6b), in good correlation with the extent of miR-375 disruption obtained by transfection.

This set of data demonstrates that the expression of miRNA375 in keratinocytes is induced by the formation of the HIVEnv synapse that in turn controls secretion of TSLP by keratinocytes. In foreskin keratinocytes, as similar to other epithelia, $^{23,24}$ the TSLP innate immune response appears therefore to be controlled by miRNA-375. 


\section{HIV-Env-induced TSLP secretion drives the relocation of LCs in human inner foreskin tissues and induces the formation of LC-T-cell conjugates}

TSLP secretion induced by HIV-Env ex vivo (Figure 4) was next evaluated morphologically in foreskin explants by immunohistochemistry (Figure 7a). TSLP was readily observed in the epidermal compartment at 4 and $24 \mathrm{~h}$ after contact with HIV-Env, but neither following exposure to CEM nor cell-free R5-tropic primary HIV-1 at any time point. TSLP secretion was also observed following tissue exposure to the TLR-4 ligand LPS for $24 \mathrm{~h}$, serving as the positive control. We have previously shown that LCs, attracted to the epidermal compartment of foreskin tissue by HIV-1-infected cells, were the first immune cell targeted by HIV-1 upon ex vivo tissue infection. ${ }^{16}$ To evaluate whether TSLP, which is known to drive immune cell chemoattraction, ${ }^{22}$ could control such relocation of LC, we first measured the expression of TSLP-R by foreskin LCs in foreskin tissues. Immunohistochemical labeling revealed that Langerin $^{+}$LCs were also TSLP-R ${ }^{+}$ (Figure $7 \mathbf{b}$ ), indicating that epidermal LCs could respond to TSLP by chemotaxis.

Next, HIV-Env were allowed to form viral synapses with foreskin tissues for $1-24 \mathrm{~h}$. LCs were then detected in the epidermal and dermal compartments of the foreskin tissue by immunohistochemistry (Figure $7 \mathrm{c}$, representative of $n=4$ explants from different individuals), and their localization quantified within the epidermal compartment as described earlier ${ }^{15,16}$ and detailed in the Methods section (Figure 7d, using $n=4$ tissue from different independent individuals counting more than 180 LCs per conditions at each time point). After contact with HIV-Env for $4 \mathrm{~h}$, Langerin ${ }^{+}$LCs migrated to the upper half of the epidermis-with an attributed thickness of $100 \%$-towards the mucosal surface in a statistically significant manner (from $25 \pm 4 \%$ of the epidermal thickness in normal tissue prior to HIV-Env inoculation to $58 \pm 7 \%$ of the epidermal thickness $4 \mathrm{~h}$ after contact with HIV-Env, $P<0.05$ ). This outward migration was followed at $24 \mathrm{~h}$ of contact with HIV-Env by an inverse inward movement toward the basement membrane at the epidermal/dermal junction, returning to baseline original position $(24.5 \pm 3.5 \%$ of the epidermal thickness). Preincubation of the tissue with an anti-TSLP $\mathrm{mAb}$ prevented this HIV-Env-induced migration of LCs. In keeping with these data, LC migration was not observed following contact of the tissue with CEM cells or in the absence of contact and LC position remained almost identical up to $24 \mathrm{~h}$ in the lower $25 \%$ of the epithelial thickness.

As we previously reported, within $4 \mathrm{~h}$ of $\mathrm{HIV}-1$ foreskin tissue infection, dermal CD3 ${ }^{+}$T-cells migrated to the epidermal compartment. ${ }^{16}$ Therefore, we next evaluated (Figure 7e, representative of $n=4$ explants from different individuals $4 \mathrm{~h}$ after contact with HIV-Env) and quantified (Figure 7f, using $n=4$ tissue from different independent individuals counting $>150$ LCs per conditions at each time point) the respective distributions of $\mathrm{CD}^{+}{ }^{+}$T-cells and Langerin ${ }^{+}$LCs by double immunolabeling of tissue explants inoculated with HIV-Env up to $24 \mathrm{~h}$. HIV-Env contact induced the formation of Langerin ${ }^{+}$ LCs conjugates with epidermal CD3 ${ }^{+}$T-cells in both epidermal and dermal compartments reaching a maximum at $4 \mathrm{~h}$. Conjugate formation was inhibited by preincubation of the tissue with anti-TSLP mAbs (densities of $60 \pm 15$ cells per $\mathrm{mm}^{2}$ vs. $20 \pm 6$ cells per $\mathrm{mm}^{2}$ after $4 \mathrm{~h}$ of contact with HIV-Env vs. HIV-Env + anti-TSLP mAb, respectively, using tissues from $n=4$ independent individuals $P<0.05$ ), whereas no conjugate formed following tissue contact with control CEM.

Altogether, TSLP secretion induced by HIV-Env results in a specific and transient LC attraction to the mucosal surface, and a redistribution of $\mathrm{CD}^{+}$T-cells accompanied by subsequent formation of LC-T-cell conjugates.

\section{DISCUSSION}

Deciphering the early events in HIV-1 transmission is of chief importance for the elaboration of $\mathrm{HIV}-1$ prophylactic strategies, as HIV-1 is mainly transmitted sexually at mucosal sites of both female and male genital tracts. Sexual HIV-1 infection is vectorized by secretions that contain HIV-1-infected cells as well as cell-free viruses; the latter being largely defective or replication incompetent. ${ }^{11}$ Furthermore in patients under antiretroviral therapy with clinically suppressed plasma viremia,

Figure 7 In foreskin explants ex vivo, TSLP secreted following HIV-Env viral synapse establishment induces LC migration towards the mucosal surface and formation of LC-T-cell conjugates. (a) Foreskin explants were inoculated with HIV-Env or parental CEM, cell-free HIV-1, or with LPS as a positive control or left unstimulated as indicated for 1, 4, and $24 \mathrm{~h}$. TSLP was detected by immunocytochemistry. Images are representative of $n=4$ independent experiments using explants from different individuals. Broken lines denotes the basement membranes, bar: $10 \mu \mathrm{m}$. (b) Foreskin epithelial LCs immunostained with anti-Langerin mAb (cyan) co-express the TSLP-R immunostained with a TSLP-R-specific mAb (brown). Bar: $10 \mu m$. Insets are shown magnified on the left and right sides of the main image. (c) Foreskin explants were inoculated for 1 , 4 , and $24 \mathrm{~h}$ with HIV-Env, with HIV-Env after

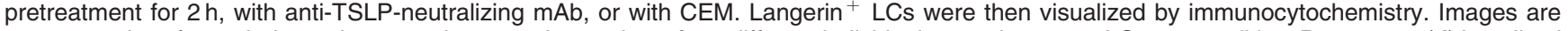
representative of $n=4$ independent experiments using explants from different individuals counting $>180$ LCs per condition. Bar: $10 \mu$ m. (d) Localization

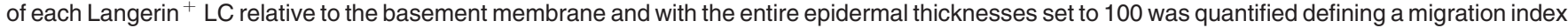
that varies between 0 and 100. Results are plotted with 0 representing the basement membrane (as pointed by the lower arrow) and 100 the mucosal surface (as pointed by the upper arrow). Shown are mean \pm s.e.m. of $n=4$ independent experiments using explants from different individuals, ${ }^{\star} P<0.05$ unpaired Students' $t$-test as compared to non-stimulated. (e) Foreskin explants were inoculated with HIV-Env for $4 \mathrm{~h}$ in the absence or after preincubation with anti-TSLP-blocking antibody. Langerin ${ }^{+}$LCs (brown) and CD3 ${ }^{+}$T-cells (cyan) were then detected simultaneously by immunocytochemistry. Filled black arrows show LC-T-cell conjugates in the epithelium (left panel) and in the stroma (right panel). Empty black arrows point to isolated LCs. Images are representative of $n=4$ independent experiments using explants from different individuals. Bar: $10 \mu \mathrm{m}$. (f) Foreskin explants were inoculated for 1,2 , and

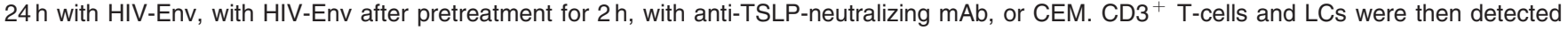
simultaneously by immunocytochemistry and total LC-T-cell conjugates quantified in both the epidermis and dermis for each condition. Values are means \pm s.e.m. of $n=4$ independent experiments using explants from different individuals counting $>150$ conjugates per conditions. E, epithelium; LC, Langerhans cell; mAb, monoclonal antibody; S, stroma; TSLP, thymic stromal lymphopoietin. 
cell-associated HIV-1 DNA frequently remains detectable in genital secretions, in contrast to an absence of cell-free HIV-1 particles. $^{31} \mathrm{HIV}-1$-infected cells represent therefore an important source of infectivity in genital secretions, which deliver infectious viruses via viral synapses. HIV-1 entry at mucosal sites following viral synapse formation of host cells with HIV-1-infected cells is now well recognized to be much more efficient than HIV-1 entry and infectivity of cell-free virus. ${ }^{10,11,15}$ However, signaling induced by viral synapse formation in mucosal CD4-negative epithelial target cells that leads to efficient HIV mucosal penetration has remained undefined.

Here using human primary foreskin keratinocytes and foreskin tissues ex vivo, we demonstrate that the HIV-1 envelope in the context of the viral synapse, but not cell-free HIV-1, is sufficient to stimulate TSLP secretion by keratinocytes in a TLR4- and NfאB-dependent manner. In turn, TSLP attracts LCs expressing the TSLP-R to the mucosal surface, facilitating the initial steps leading to HIV-1 entry in the foreskin epidermis as we reported earlier. ${ }^{15}$ Finally, in response to viral synapse a

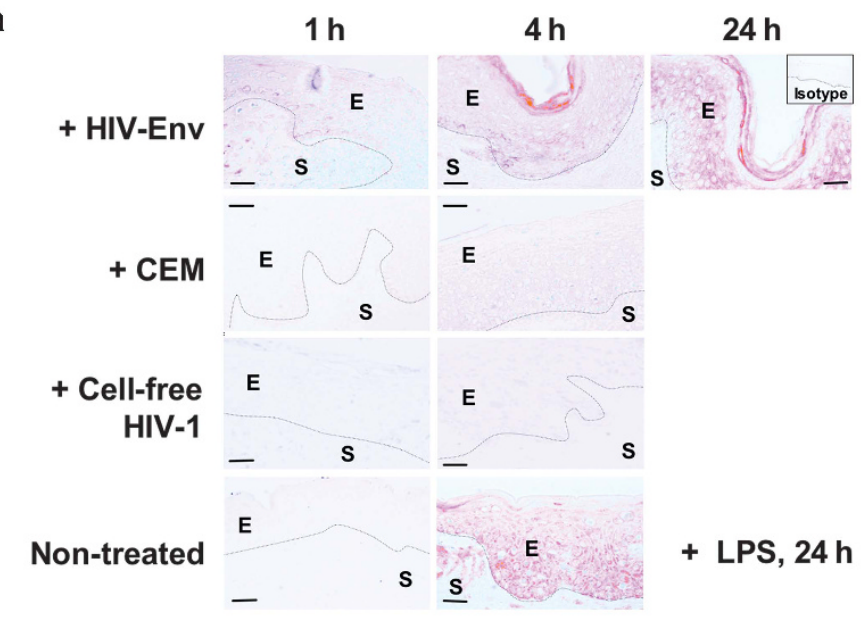

c

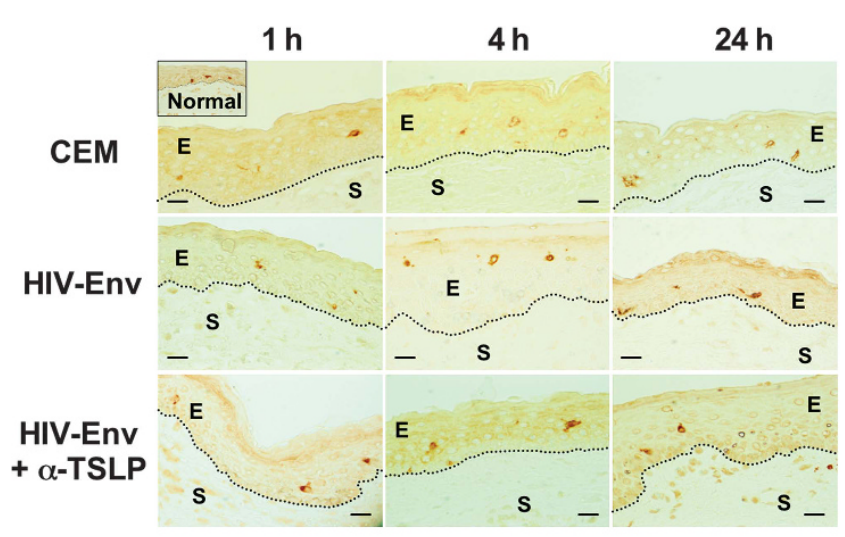

e

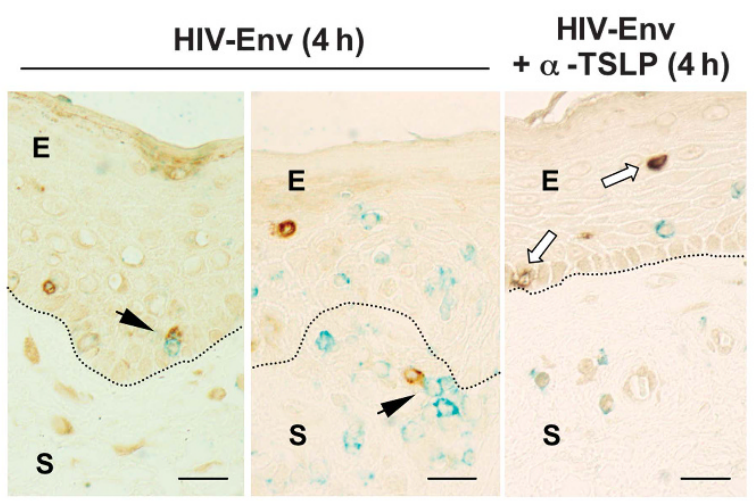

b

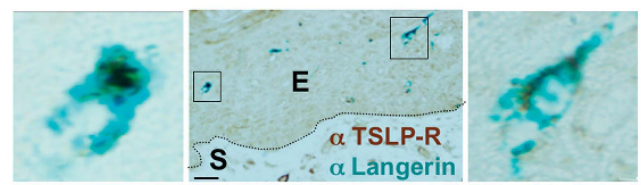

d

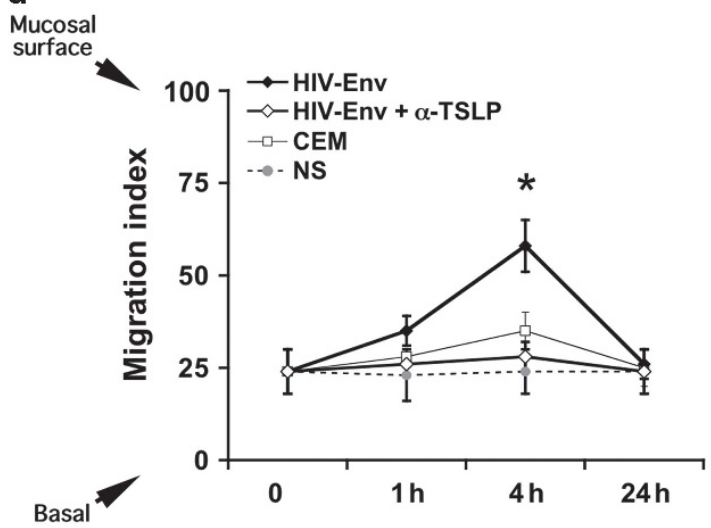

f

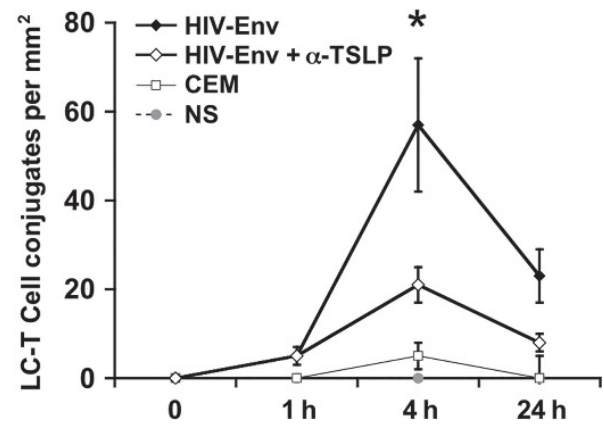


formation the human miRNA, miR-375 is upregulated and in turn controls mucosal secretion of TSLP in human keratinocytes.

The mechanism driving viral synapse formation between HIV-1-infected cells and immune CD4 + target cells relies on LFA-1 integrin and corresponding desintegrin interaction, and the local reorganization of the target cell plasma membrane. ${ }^{5,32}$ Accordingly, keratinocyte express ICAM-1 and -3 but lack LFA-1 expression. Such viral synapses mimic the immunological synapses formed between antigen-presenting cells and T-cells. ${ }^{32,33}$ In rectal and genital tissues such as urethra, vagina, cervix, and foreskin that express ICAM- 1 and -3 but lack LFA1, HIV-1-infected cells can also form viral synapses with mucosal epithelial cells. These mucosal epithelial cells lack CD4 and express low co-receptors allowing for HIV-1 cell-free particles produced locally in the synaptic cleft to enter into and translocate through the epithelium (Supplementary Figure S3 online) and..$^{9,10,15}$ Previous studies reported the involvement of heparan sulfate proteoglycan and integrins such as LFA-1 and matching desintegrins in viral synapse formation and stability, leading to efficient HIV-1 entry into CD4-negative monostratified epithelium. ${ }^{10}$ We now show that LFA- $1 \alpha / \beta$ and ICAM-1/3 cooperate with gp120 to allow HIV-1 envelopeexpressing cells to adhere to a pluristratified epithelium, such as the foreskin one. The formation of the polarized viral synapse we observed here with foreskin cells requires a period of $30 \mathrm{~min}$ to $1 \mathrm{~h}$ to become stabilized. This time period is most likely necessary for virus to be produced in the synaptic cleft and internalized by epithelial cells, as observed in simple epithelium ${ }^{8}$ or in the human urethra. ${ }^{9}$ It is thus longer than the

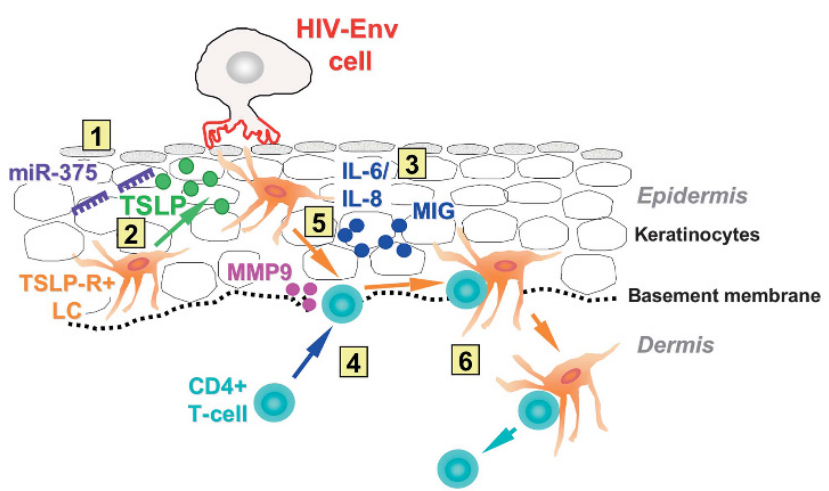

Figure 8 "Chain of events" induced by HIV-1-envelope-mediated viral synapse facilitating HIV-1 entry in the human foreskin. (1) HIV-1-infected CD4 + T-cells form a viral synapse with foreskin keratinocytes. HIV-1 envelope gp120 in the context of the viral synapse interacts with TLR-4, initiates the MyD88-independent NfkB signaling cascade leading to the secretion of various cytokines including TSLP, IL-6/IL-8, MIG, and MMP-9. In parallel, HIV-1-envelope-mediated viral synapse stimulates the expression of miRNA-375, a regulator of TSLP. (2) TSLP attracts epidermal LCs to the mucosal surface to capture HIV-1 produced extemporaneously in the viral synaptic cleft. (3) Viral synapse-induced IL6/IL-8 and MIG attract dermal CD4 ${ }^{+} \mathrm{T}$-cell to the epidermal compartment. (4) Viral synapse-induced MMP-9 degrades the basement membrane allowing for dermal $\mathrm{CD} 4^{+} \mathrm{T}$-cell penetration into the epidermal compartment. (5) HIV-1 ${ }^{+}$LCs migrate back toward the basement membrane and meet CD4 ${ }^{+}$T-cells to form conjugates, allowing for HIV-1 transfer from LCs to T-cells. (6) The LC-T-cell conjugates translocate to the dermis to disseminate infection. LC, Langerhans cell; MMP-9, matrix metalloproteinase; TSLP, thymic stromal lymphopoietin.
2-10 min time period required by the synapse formed between isolated mononuclear cells in vitro that results in rapid infection of $\mathrm{CD} 4{ }^{+}$T-target cells. ${ }^{34}$

The signaling cascade initiated by the trimeric HIV-1 envelope in the context of viral synapses with foreskin keratinocytes engages TLR-4, a receptor not previously reported to be involved in viral synapse formation, but intensively studied in innate immunity. ${ }^{29}$ An active role of TLR- 4 in epithelial cells is indeed in agreement with recent studies reviewed by Nestles et al. ${ }^{17}$ reporting on the capacity of keratinocytes to act as sensors of danger through TLR and to perform, in turn, critical innate immune functions. ${ }^{35}$ Here, we found that TLR-4 expressed on foreskin epithelial keratinocytes, but not keratinocyte-expressed TLR-2 nor TLR-9 (data not shown), is activated by gp120 in the context of the viral synapse, in agreement with previous observations. ${ }^{36}$ Hence, in addition to recognition of canonical ligands such as LPS for TLR-4, or double-stranded RNA for TLR-3, TLR have been shown to recognize and be activated by various viral envelope proteins. ${ }^{37,38}$ In the context of the viral synapse, gp120 activation of TLR-4 induces signaling via IкB $\alpha$ and nuclear translocation of the NfkB subunit p65.

The analysis of phosphorylated proteins induced specifically by the HIV-Env-dependent synapse, performed in parallel to TLR-4 functional analyses, provides a broader view of HIVenvelope-induced signaling cascade, and reveals a bridge with mucosal innate immunity. The specific pattern of protein phosphorylation induced by HIV-1 envelope-mediated synapse in foreskin epithelial cells uncovers the activation of a MyD88-independent NfאB signaling cascade. In turn, this triggers the release of several pro-inflammatory soluble factors such as IL-6, IL-8, MIG, and MMP-9, as well as TSLP. This is in agreement with the MyD88-independent blockade of I $\mathrm{B} \alpha$ expression by the viral synapse we observed (Figure 2d), and with the translocation of p65 to the nucleus (Figure 3) that results from I $\mathrm{I} \mathrm{B} \alpha$ and $\mathrm{p} 65$ phosphorylation. In agreement with the phosphoarray analysis, multiplex protein analyses showed that IL-6, IL-8, MIG, and MMP-9 are secreted following the formation of the HIV-1-envelope-dependent synapse. Moreover, we found that the T-helper type 2-biased cytokine, TSLP, is also specifically secreted in response to the viral synapse both in keratinocytes in the in vitro mucosal reconstruction, and in foreskin tissues ex vivo. The significant induction of TSLP is tightly regulated by the expression of the non-coding small RNA, miR-375, as suggested by the pathway analysis, and confirmed in the foreskin reconstructed epithelium. Hence there, the HIV-Env viral synapse stimulates miR-375 expression, whereas anti-mir-375 transfection blocks HIV-Env-mediated TSLP secretion (Figure 6). Altogether, these data suggest that the HIV-1-envelope-mediated viral synapse hijacks the signaling of TLR-4 by triggering the signaling cascade using miR-375 to induce a rapid release of TSLP.

TSLP has been hypothesized not only to induce DC activation, which may have an impact on their capacity to transmit HIV-1 following cell-free HIV-1-induced secretion by epithelial cell lines, ${ }^{30}$ but also to act as a chemoattractant for 
DCs. ${ }^{22}$ Applied to LCs in genital pluristratified mucosa, these two activities of TSLP could participate in HIV-1 penetration into mucosal tissue following viral synapse formation. Hence, in human foreskin tissues ex vivo, the rapid release of TSLP by keratinocytes following viral synapse formation correlates with the transient attraction of LC-expressing TSLP-R to the mucosal pole. This mechanism is blocked by anti-TSLPblocking mAbs. Once at the mucosal pole, LCs could capture the virus produced in the synaptic cleft by extending dendrites or after transcytosis across the surface layers of keratinocytes (Supplementary Figure S3 online and Ganor et al. ${ }^{15}$ ). In turn, LCs activated by the uptake of HIV and/or TSLP binding could migrate back toward the dermis to form conjugates with $\mathrm{CD} 4{ }^{+}$ T-cells as we have observed (Figure 7) and disseminate infection. This biphasic movement of LCs towards the mucosal surface and then back towards the basal level is in agreement with our previous studies using HIV-1-infected cells forming viral synapses that mediate infection of foreskin tissues. ${ }^{9}$ In contrast, the lack of TSLP secretion following interaction with cell-free virus indicates that the gp120/TLR-4/NfאB signaling cascade leading to TSLP secretion can only result from gp120/ TLR-4 activation within the context of the viral synapse, although the role of signals induced individually by either gp120/TLR-4 interaction or synaptic integrin/desintegrin contact remains to be clarified.

The other innate immune factors secreted following the formation of the viral synapse, namely, IL-6, IL-8, MIG, and MMP-9, could contribute to the microenvironment favorable for efficient transmission of HIV-1 in foreskin mucosa. The pro-inflammatory cytokines IL- 6 and IL- 8 could serve as innate immune factors activating mucosal immune cells including LCs and T-cells expressing respective receptors. MIG, a T-cell chemoattractant/chemokine, could participate in $\mathrm{CD} 4{ }^{+} \mathrm{T}$-cell migration allowing for conjugate formation with LCs, after mucosal virus capture and subsequent migration back towards the basement membrane, followed by transfer of the virus as we observed both here and previously. Finally, the enzyme MMP-9 could play an important role in facilitating LC migration from the epithelium to the luminal surface through the basement membrane. ${ }^{39}$

On the basis of the present study, we propose (Figure 8) that the signaling induced by the viral synapse mediated by the HIV envelope, which initiates HIV-1 entry in the foreskin, relies mainly on the interaction of gp120 with keratinocyte TLR-4 within the synaptic cleft of the synapse. Such interaction induces signals that permit LCs, the first target of the virus in human foreskin, to access the mucosal surface. There, LCs capture locally produced virus in the synaptic cleft, before returning deeper into the tissue where they propagate infection to $\mathrm{CD} 4^{+} \mathrm{T}$-cells.

Understanding the signaling events driven by the viral synapse could help to define novel anti-viral strategies against sexual transmission of HIV-1 by targeting TSLP or miR-375. These studies provide novel information that advances our understanding of the complex regulation of innate immune responses initiated by HIV-1 during sexual transmission.

\section{METHODS}

Ethical statement. The study was performed according to local ethical regulations, following approval by the local ethical committee (Comite de Protection des Personnes (CPP), île de France XI, approval no. 11 016). Written informed consent was provided by all study participants.

Cells. HIV-Env, a human lymphoblastic CXCR $4{ }^{+} \mathrm{CCR} 5{ }^{-} \mathrm{CD} 4{ }^{+}-\mathrm{T}$ CEM cell line expressing a functional HIV-1 envelope made of trimeric spikes of the gp 41 and gp120 subunits from HIV-1 IIIb clone, ${ }^{25}$ and the parental CEM cell line, as well as $\mathrm{CD} 4{ }^{+} \mathrm{T}$-lymphocytes chronically infected by HIV-1 NDK (CEM-NDK) were cultivated in RPMI 1650 (Gibco, Villebon-sur-Yvette, France) complemented with 1\% penicillin and $1 \%$ streptomycin, $1 \%$ L-glutamine, and $10 \%$ fetal calf serum (Biowest, Nuaillé, France).

Flow cytometry. For immunofluorescent staining, cells were surface stained with primary mouse $\mathrm{mAbs}\left(10 \mu \mathrm{g} \mathrm{ml}^{-1}\right)$ against CD1la, CD18, CD50, CD54 (ImmunoTools), or human anti-gp120 2G12 or anti-gp41 2F5 or $98.6 \mathrm{mAbs}$ (NIH AIDS reagents program) followed by mouse-specific FITC-conjugated Abs $\left(5 \mu \mathrm{g} \mathrm{ml}{ }^{-1}\right.$, Jackson Immunotech, Montlucon, France), or incubated directly with FITCconjugated CD29, CD45, HLA-DR, $(10 \mu \mathrm{l}$ per test, BD Pharmingen, San Jose, CA), FITC-conjugated CD49e, CD49f (10 $\mu$ l per test, ImmunoTools, Gladiolenweg, Germany). Fluorescence profiles $(5,000$ events) were acquired with a FACSCalibur (BD Biosciences, Le Pont de Claix, France) and analyzed with CellQuest Pro (BD Biosciences).

Tissues. Normal foreskin tissues were obtained from the Urology Service at the Cochin Hospital, Paris, France, from healthy adults (mean age 33 years old, range 18-55 years) undergoing elective circumcision due to personal reasons or phimosis, and according to local ethical regulations as described. ${ }^{16}$ Inner foreskin keratinocytes were purified from inner foreskin tissues as described ${ }^{16}$ and lacked CCR5 expression as measured by flow cytometry.

In vitro simplified reconstructed foreskin epithelium model. For live imaging of the viral synapse, purified keratinocytes $\left(0.8 \mathrm{~cm}^{2}\right.$ per well, 0.5 million cells per well) were cultured for $72 \mathrm{~h}$ in an eight-well Ibidi chamber system (Biovalley, Nanterre, France) precoated with $2.5 \mu \mathrm{g} \mathrm{cm}^{-2}$ collagen I and $2.5 \mu \mathrm{g} \mathrm{cm}^{-2}$ fibronectin (Sigma). For confocal microscopy imaging of the viral synapse, primary keratinocytes $\left(1.0 \mathrm{~cm}^{2}\right.$ per well, 0.5 million cells per well in $0.5 \mathrm{ml} \mathrm{KSFM} 10 \%$ fetal calf serum) were cultured for $72 \mathrm{~h}$ in eight-well Permanox slides (ThermoFischer, Villebon-sur-Yvette, France) precoated as above. For western blot and cytokine measurement, primary keratinocytes $(0.5$ million cells per well) were cultured for $72 \mathrm{~h}$ in 6 - or 24 -well plates, respectively, precoated as above. Under these culture conditions, keratinocytes formed a three- to five-layer-thick mucosa (Supplementary Figure SD1 online), that is polarized as evaluated by polarized cytokeratin 14 distribution in immunofluorescence using a cytokeratin 14 specific mAb (Abcam, Paris, France; not shown).

Live wide-field microscopy imaging. HIV-Env and parental CEM CD4 ${ }^{+}$T-cells were labeled with CMFDA (Life Technologies, Villebon-sur-Yvette, France, $0.17 \mathrm{ng} \mathrm{ml}^{-1}$ ), preincubated when indicated with specific antibodies, and inoculated onto reconstructed epithelium. T-cell attachment was evaluated by live wide-field microscopy with an epifluorescent microscope (Axio Observer, Zeiss, Marly-Le-Roi, France) using the green channel for CMFDA T-cells tracking, with simultaneous differential interference contrast recording to visualize keratinocytes.

Nf $\kappa$ B p65 nuclear translocation assayed by immunofluorescent staining and confocal microscopy analysis. Epithetial reconstruction in Permanox wells were inoculated with 0.5 million of either HIV-Env or CEM or with $100 \mathrm{ng} \mathrm{ml}^{-1}$ LPS (Sigma) for $1-4 \mathrm{~h}$. Cells were fixed, permeabilized, and immunostained with rabbit anti-p65 $\left(1 \mu \mathrm{g} \mathrm{ml}^{-1}\right)$ followed by DyLight594-conjugated anti-rabbit IgG $\left(5 \mu \mathrm{g} \mathrm{ml}^{-1}\right.$, Jackson Immuno-Research). Cell nuclei were then stained 
with 4,6-diamidino-2-phenylindole $\left(5 \mu \mathrm{g} \mathrm{ml}^{-1}\right.$, Sigma). Samples were observed using a Leica DMI6000 confocal microscope (Leica Microsystems, Nanterre, France) as described. ${ }^{16}$ Signals were processed based on established parametric settings using specific isotype controls and the localization of p65 relative with cell nucleus analyzed as reported. ${ }^{40}$

Immunoblotting. When indicated, the mucosal reconstructions were preincubated with Poly I:C $\left(25 \mu \mathrm{g} \mathrm{ml}^{-1}, 1 \mathrm{~h}\right.$ at $37^{\circ} \mathrm{C}$, Invivogen, Toulouse, France), LPS (100 ng ml ${ }^{-1}, 1 \mathrm{~h}$ at $37^{\circ} \mathrm{C}$, Sigma,) or various $\mathrm{Nf} \kappa \mathrm{B}$ inhibitors 4-hydroxynonenal $\left(1 \mu \mathrm{M}, 1 \mathrm{~h}\right.$ at $37^{\circ} \mathrm{C}$, Enzo Life Science, Villeurbanne, France), Pepinh-MYD $\left(1 \mu \mathrm{M}, 30 \mathrm{~min}\right.$ at $37^{\circ} \mathrm{C}$, Invivogen) and TLR-4-neutralizing antibody $\left(10 \mu \mathrm{g} \mathrm{ml}^{-1}, 1 \mathrm{~h}\right.$ at $37^{\circ} \mathrm{C}$, Invivogen). Lymphocytes were then incubated with the reconstructed epithelia for 1-24h. Cells were lyzed, and protein content was quantified by BCA (ThermoFisher) according to the manufacturer's instructions and identical protein amounts $(10-20 \mu \mathrm{g})$ in each condition analyzed for TLR-3 (Abcam, $10 \mu \mathrm{g} \mathrm{ml}^{-1}$ ), TLR-4 (Santa Cruz, Heidelberg, Germany, $\left.0.25 \mu \mathrm{g} \mathrm{ml}^{-1}\right)$, I $\mathrm{B} \alpha($ Cell Signalling, Leiden, The Netherlands, 1:1,000), and $\beta$-actin (Cell Signalling, 1:1,000) by immunoblotting.

Ex vivo foreskin tissue explants. Normal foreskin tissue explants were obtained and processed as we previously reported. ${ }^{9,15,16}$ HIV-Env or CEM cells $(0.5$ million per $100 \mu \mathrm{l})$ were inoculated mucosaly in a polarized manner for 1-24 h. Culture media were collected and stored at $-80{ }^{\circ} \mathrm{C}$, tissues were washed, and fixed in $4 \%$ paraformaldehyde (Electron Microscopy Sciences, Hatfield, PA), and embedded in paraffin for semi-thin section preparation.

Immunohistochemistry. Foreskin tissue semi-thin sections were obtained from the Anatomo-Pathologie Department (Cochin Hospital), processed and analyzed as described. ${ }^{16} \mathrm{LC}$ distributions were detected as we reported ${ }^{16}$ on at least 10 sections per individuals. ${ }^{9,15,16}$ Briefly, normal distances of LCs to the epidermal mucosal surfaces and basement membrane, as well as the epidermal thickness (normal distance between epidermal surface and the basement membrane) were evaluated using Image-J and then processed using the Arcgis V9.3 program (ESRI, Redlands, CA). LC distance index was calculated as follows:

Distance index $=1-$ (distance of LC to the epidermal surface/ epidermal thickness).

Chemokines and cytokines quantification. Using culture media, TSLP and CCL20 were measured by enzyme-linked immunosorbent assay (eBioscience, Villebon-sur-Yvette, France), and CCL5, IL-6, IL8 , MIG, MMP-9, G-CSF, IFN- $\gamma$, MIP- $1 \alpha$, MIP- $1 \beta$, MCP-1, and TNFalpha with a custom multiplex bead immunoassay kit (Flowcytomix, eBioscience) according to the manufacturer's instructions.

Phosphoarray. Protein phosphorylation was quantified using the Human Phospho-Kinase Array Kit (R\&D Systems, Minneapolis, MN) according to the manufacturer's instructions. The signals were detected using the ECL Plus Western Blotting Detection System (GE Healthcare, Vélizy-Villacoublay, France), and quantified with dedicated Image-J software. Specific phosphorylation signal was calculated as the ratio between HIV-Env- and CEM-induced phosphorylation, and resulting signaling network analyzed using Quiagen Ingenuity Pathway analysis (Redwood City, CA) and Elsevier's Pathway Studio software (Issy-les-Moulineaux, France).

Quantitative PCR. The expression of hsa-miR-375 was evaluated as reported. ${ }^{23,41}$ Briefly, total RNA was extracted from keratinocytes with the miRNeasy Mini Kit (Qiagen, Courtaboeuf, France), and subjected to reverse transcription and analyzed by specific quantitative PCR with TaqMan Small RNA Assays (hsa-miR-375: 000564 U6 snRNA: 001973; Applied Biosystems, Villebon-sur-Yvette, France). U6 small nuclear RNA was used as the reference gene.

Transfection of miRNA-375 inhibitor. The transfection of miR-375 inhibitor was evaluated as reported ${ }^{24,42}$ Keratinocytes were seeded in a 12 -well fibronectin $\left(2.5 \mu \mathrm{g} \mathrm{cm}^{-2}\right)$ - and collagen $\left(2.5 \mu \mathrm{g} \mathrm{cm}^{-2}\right)$-coated plate. After cells reached $70-80 \%$ confluence, keratinocytes were transfected with a miRNA inhibitor (anti-hsa-miR-375; $75 \mathrm{~nm}$; miSCRIPT, MIN0000728; Qiagen) ${ }^{24}$ or mock inhibitor (anti-miR control; $75 \mathrm{~nm}$; miSCRIPT inhibitor negative control; Qiagen) ${ }^{24}$ using Lipofectamine RNAiMAX (Invitrogen) according to the manufacturer's instructions. To assess transfection efficiency, we routinely transfected control cells with AllStars Hs Cell Death siRNA (75 nm; Qiagen), and cell death were quantified with alamarBlue Assays. As a result, transfection efficiencies were 50-55\%. Furthermore, $60 \mathrm{~h}$ after transfection, miR-375 expression was quantified by quantitative PCR as described above and miR-375 was reduced by $53 \pm 3 \%$ in anti-miR375 transfected cells as compared to anti-miR control $(n=4$ independent experiments).

Statistical analysis. Statistical significance was analyzed by the twotailed Student's or paired $t$-test. For analysis of equivalence of variations of $\mathrm{Nf \kappa B}$ p 65 signal, Levene's test was used prior to performing Student's $t$-test.

SUPPLEMENTARY MATERIAL is linked to the online version of the paper at http://www.nature.com/mi.

\section{ACKNOWLEDGMENTS}

YG was supported by Agence National de Recherche sur le SIDA et les Hépatites (ANRS) fellowship, ZZ by ANRS and Fondation pour la Recherche Médicale fellowships, and LX by the China Scholarship Council fellowship. MB was supported by grants from ANRS. We thank Dr B. Weksler for English editing.

\section{AUTHOR CONTRIBUTIONS}

$M B, Z Z$, and $L X$ conceived and designed the experiments, ZZ, LX, AS, CD, $Y G, D T, D D, D B D, Z Z$, and MB performed the experiments. ZZ, LX, AS, CD, and $M B$ analyzed the data. $Z Z$ and MB wrote the paper.

\section{DISCLOSURE}

The authors declared no conflict of interest.

c) 2018 Society for Mucosal Immunology

\section{REFERENCES}

1. Engering, A. et al. The dendritic cell-specific adhesion receptor DC-SIGN internalizes antigen for presentation to Tcells. J. Immunol. 168, 2118-2126 (2002).

2. Arrighi, J.F. et al. DC-SIGN-mediated infectious synapse formation enhances X4 HIV-1 transmission from dendritic cells to T cells. J. Exp. Med. 200, 1279-1288 (2004).

3. Groot, F., Welsch, S. \& Sattentau, Q.J. Efficient HIV-1 transmission from macrophages to T cells across transient virological synapses. Blood 111, 4660-4663 (2008).

4. McDonald, D., Wu, L., Bohks, S.M., KewalRamani, V.N., Unutmaz, D. \& Hope, T.J. Recruitment of HIV and its receptors to dendritic cell-T cell junctions. Science 0, 1295-1297 (2003).

5. Jolly, C., Kashefi, K., Hollinshead, M. \& Sattentau, Q.J. HIV-1 cell to cell transfer across an Env-induced, actin-dependent synapse. J. Exp. Med. 199, 283-293 (2004).

6. Krementsov, D.N., Weng, J., Lambele, M., Roy, N.H. \& Thali, M. Tetraspanins regulate cell-to-cell transmission of HIV-1. Retrovirology 6, 64 (2009).

7. Bomsel, M. et al. Intracellular neutralization of HIV transcytosis across tight epithelial barriers by anti-HIV envelope protein dlgA or IgM. Immunity 9, 277-287 (1998)

8. Bomsel, M. Transcytosis of infectious human immunodeficiency virus across a tight human epithelial cell line barrier. Nat. Med. 3, 42-47 (1997).

9. Ganor, Y. et al. The adult penile urethra is a novel entry site for HIV-1 that preferentially targets resident urethral macrophages. Mucosal Immunol. 6, 776-786 (2013).

10. Alfsen, A., Yu, H., Magerus-Chatinet, A., Schmitt, A. \& Bomsel, M. HIV-1infected blood mononuclear cells form an integrin- and agrin-dependent viral synapse to induce efficient HIV-1 transcytosis across epithelial cell monolayer. Mol. Biol. Cell 16, 4267-4279 (2005). 
11. Anderson, D.J., Politch, J.A., Nadolski, A.M., Blaskewicz, C.D., Pudney, J. \& Mayer, K.H. Targeting Trojan Horse leukocytes for HIV prevention. Aids 24, 163-187 (2010).

12. Duncan, C.J. et al. High-multiplicity HIV-1 infection and neutralizing antibody evasion mediated by the macrophage-T cell virological synapse. J. Virol. 88, 2025-2034 (2014).

13. Chen, P., Hubner, W., Spinelli, M.A. \& Chen, B.K. Predominant mode of human immunodeficiency virus transfer between $T$ cells is mediated by sustained Env-dependent neutralization-resistant virological synapses. J. Virol. 81, 12582-12595 (2007).

14. Ganor, Y. \& Bomsel, M. HIV-1 transmission in the male genital tract. Am. J. Reprod. Immunol. 65, 284-291 (2011).

15. Ganor, Y. et al. Within $1 \mathrm{~h}, \mathrm{HIV}-1$ uses viral synapses to enter efficiently the inner, but not outer, foreskin mucosa and engages Langerhans-T cell conjugates. Mucosal Immunol. 3, 506-522 (2010).

16. Zhou, Z. et al. HIV-1 efficient entry in inner foreskin is mediated by elevated CCL5/RANTES that recruits T cells and fuels conjugate formation with Langerhans cells. PLoS Pathog. 7, e1002100 (2011).

17. Nestle, F.O., Di Meglio, P., Qin, J.Z. \& Nickoloff, B.J. Skin immune sentinels in health and disease. Nat. Rev. Immunol. 9, 679-691 (2009).

18. Lebre, M.C. et al. Human keratinocytes express functional Toll-like receptor 3, 4, 5, and 9. J. Invest. Dermatol. 127, 331-341 (2007).

19. Soumelis, V. et al. Human epithelial cells trigger dendritic cell mediated allergic inflammation by producing TSLP. Nat. Immunol. 3, 673-680 (2002).

20. Lee, H.C. \& Ziegler, S.F. Inducible expression of the proallergic cytokine thymic stromal lymphopoietin in airway epithelial cells is controlled by NFkappaB. Proc. Natl Acad. Sci. USA 104, 914-919 (2007).

21. Vu, A.T. et al. Extracellular double-stranded RNA induces TSLP via an endosomal acidification- and NF-kappaB-dependent pathway in human keratinocytes. J. Invest. Dermatol. 131, 2205-2212 (2011).

22. Fernandez, M.I. et al. The human cytokine TSLP triggers a cellautonomous dendritic cell migration in confined environments. Blood 118, 3862-3869 (2011).

23. Biton, M. et al. Epithelial microRNAs regulate gut mucosal immunity via epithelium-T cell crosstalk. Nat. Immunol. 12, 239-246 (2011).

24. Bleck, B. et al. MicroRNA-375 regulation of thymic stromal lymphopoietin by diesel exhaust particles and ambient particulate matter in human bronchial epithelial cells. J. Immunol. 190, 3757-3763 (2013).

25. Keler, T., Li, H., Cloyd, M.W., Vitale, L.A. \& Deo, Y.M. Development of T-cell lines expressing functional HIV-1 envelope glycoproteins for evaluation of immune responses in HIV-infected individuals. J. Acquir. Immune Defic. Syndr. Hum. Retrovirol. 13, 117-126 (1996).

26. Sigal, A. et al. The LFA-1 integrin supports rolling adhesions on ICAM-1 under physiological shear flow in a permissive cellular environment. J. Immunol. 165, 442-452 (2000).
27. Tjomsland, V. et al. Blocking of integrins inhibits HIV-1 infection of human cervical mucosa immune cells with free and complement-opsonized virions. Eur. J. Immunol. 43, 2361-2372 (2013).

28. Newman-Smith, E., Kourakis, M.J., Reeves, W., Veeman, M. \& Smith, W.C. Reciprocal and dynamic polarization of planar cell polarity core components and myosin. Elife 4, e05361 (2015).

29. Kawai, T. \& Akira, S. Toll-like receptor downstream signaling. Arthritis Res. Ther. 7, 12-19 (2005).

30. Fontenot, D. et al. TSLP production by epithelial cells exposed to immunodeficiency virus triggers DC-mediated mucosal infection of CD4 + T cells. Proc. Natl Acad. Sci. USA 106, 16776-16781 (2009).

31. Henning, T.R., Kissinger, P., Lacour, N., Meyaski-Schluter, M., Clark, R. \& Amedee, A.M. Elevated cervical white blood cell infiltrate is associated with genital HIV detection in a longitudinal cohort of antiretroviral therapyadherent women. J. Infect. Dis. 202, 1543-1552 (2010).

32. Tardif, M.R. \& Tremblay, M.J. LFA-1 is a key determinant for preferential infection of memory CD4 + Tcells by human immunodeficiency virus type 1. J. Virol. 79, 13714-13724 (2005).

33. Sol-Foulon, N. et al. ZAP-70 kinase regulates HIV cell-to-cell spread and virological synapse formation. EMBO J. 26, 516-526 (2007).

34. Martin, N., Welsch, S., Jolly, C., Briggs, J.A., Vaux, D. \& Sattentau, Q.J. Virological synapse-mediated spread of human immunodeficiency virus type 1 between Tcells is sensitive to entry inhibition. J. Virol. 84, 3516-3527 (2010).

35. Schabbauer, G. et al. TLR4/CD14-mediated PI3K activation is an essential component of interferon-dependent VSV resistance in macrophages. Mol. Immunol. 45, 2790-2796 (2008).

36. Nazli, A. et al. HIV-1 gp120 induces TLR2- and TLR4-mediated innate immune activation in human female genital epithelium. J. Immunol. 191, 4246-4258 (2013).

37. Kurt-Jones, E.A. et al. Pattern recognition receptors TLR4 and CD14 mediate response to respiratory syncytial virus. Nat. Immunol. 1, 398-401 (2000).

38. Boehme, K.W. \& Compton, T. Innate sensing of viruses by toll-like receptors. J. Virol. 78, 7867-7873 (2004).

39. Ratzinger, G. et al. Matrix metalloproteinases 9 and 2 are necessary for the migration of Langerhans cells and dermal dendritic cells from human and murine skin. J. Immunol. 168, 4361-4371 (2002).

40. Shen, R. et al. Stromal down-regulation of macrophage CD4/CCR5 expression and NF-kappaB activation mediates HIV-1 non-permissiveness in intestinal macrophages. PLoS Pathog. 7, e1002060 (2011).

41. Shi, R. \& Chiang, V.L. Facile means for quantifying microRNA expression by real- time PCR. Biotechniques 39, 519-525 (2011).

42. Vu, A.T. et al. Extracellular double-stranded RNA induces TSLP via an endosomal acidification- and NF-kB-dependent pathway in human keratinocytes. J. Invest. Dermatol. 131, 2205-2212 (2011). 